\title{
A Critical Assessment of the Mott-Schottky Analysis for the Characterisation of Passive Film-Electrolyte Junctions ${ }^{1,2}$
}

\author{
F. La Mantia ${ }^{a}$, H. Habazaki ${ }^{b}$, M. Santamaria ${ }^{c}$, and F. Di Quarto ${ }^{c, z}$ \\ ${ }^{a}$ Department of Materials Science and Engineering, Stanford University, Stanford, California 94305 \\ ${ }^{b}$ Graduate School of Engineering, Hokkaido University, Sapporo 060-8628, Japan \\ ${ }^{c}$ Dipartimento di Ingegneria Chimica dei Processi e dei Materiali, Universitá di Palermo, Viale delle Scienze, \\ 90128 Palermo, Italy \\ Received January 19, 2010
}

\begin{abstract}
The widespread use of the Mott-Schottky plots to characterize the energetics of passive film/electrolyte junction is critically reviewed in order to point out the limitation of such approach in describing the electronic properties of passive film as well in deriving the correct location of the characteristic energy levels of the junction. The frequency dependency of $\mathrm{M}-\mathrm{S}$ plots frequently observed in the experimental data gathered in a sufficiently large range of frequency is extensively discussed for a relatively thick (160 nm) thermally aged amorphous niobia $\left(\alpha-\mathrm{Nb}_{2} \mathrm{O}_{5}\right)$ film immersed in electrolytic solution. The relatively simple equivalent electrical circuit describing an ideally blocking behaviour of the junction allows a direct comparison of the experimental data analysis based on the use of Mott-Schottky or amorphous semiconductor Schottky barrier interpretative models. Moreover the theoretical simulations of the $\mathrm{M}-\mathrm{S}$ plots based on the theory of crystalline semiconductor suggest an electronic structure of the investigated passive film containing a distribution of localized electronic states deep lying in energy in agreement with the model of amorphous semiconductor Schottky barrier.
\end{abstract}

Keywords: Mott-Schottky plots, passive films, a-SC Schottky barrier, niobia

DOI: $10.1134 / \mathrm{S} 102319351011011 \mathrm{X}$

\section{INTRODUCTION}

The importance of semiconducting properties of passive film in determining both the electron and ion transfer processes at the metal/oxide and oxide/electrolyte interface is widely recognized [1-3]. Both these processes play a fundamental role in the mechanism of film dissolution and breakdown as well as in determining also the rate of localized corrosion process $[4,5]$. As for the dissolution processes of semiconducting film the thermodynamic predictions based on the theory of semiconductor/electrolyte interface can help to predict the possible reactions occurring at this interface with the participation of the surface film itself [6-8]. In the case of localized corrosion the rate of electron transfer process, necessary to sustain the cathodic reaction coupled to anodic localized process, depends on a complex interplay between the nature of redox couple (through the redox potential, $E_{\text {red/ox }}$, as well as the exchange current density parameter, $i_{0}$ ) present in solution, the corrosion potential, $U_{\text {corr }}$, and the flat band potential, $U_{\mathrm{fb}}$, of the semiconducting pas-

\footnotetext{
${ }^{1}$ The article is published in the original.

2 The paper was prepared for a special issue dedicated to the birth centenary of Ya.M. Kolotyrkin.

$z^{z}$ Corresponding author: diquarto@unipa.it (F. Di Quarto).
}

sive film and its conductivity ( $p$ or $n$-type). In any case the location of the characteristic energy levels of the metal/passive film/electrolyte junction is the preliminary task for a deeper understanding of the mechanism of corrosion at a molecular level. According to this a large effort of research has been dedicated in the last years to the study of the semiconducting properties of passive films and corrosion layers [3]. In this frame the main task for a correct location of the characteristic levels of the passive film/electrolyte junction ( $U_{\mathrm{fb}}$, conduction band edge, $E_{\mathrm{C}}$, valence band edge, $\left.E_{\mathrm{V}}\right)$ is to get a reliable measurement of the flat band potential as well as the distance in energy between the Fermi level of the passive film, coincident with the $U_{\mathrm{fb}}$ in the suitable scale of energy, and the nearest characteristic level of the semiconductor $E_{\mathrm{C}}$ ( $n$-type SC) or $E_{\mathrm{V}}$ (p-type SC). The third characteristic level is derived once the value of band gap (or mobility gap for amorphous material) is known. The most frequently employed method to derive the $U_{\mathrm{fb}}$ value is by means of differential capacitance measurements and their representation in the classical Mott-Schottky plots. This last theory, initially used for solid state junction, has been validated also for solid-liquid junction trough the fifties $[9,10]$ in several classical papers $[11,12]$ and books [13-15]. 
A special role, in the validation of the Mott-Schottky analysis also for the semiconductor/electrolyte (SC/E1) junction, was played by the classical work of Dewald on single crystal $\mathrm{ZnO} /$ electrolyte interface $[11,12]$ which provided to the electrochemists a new route for a deeper understanding of the structure of $\mathrm{SC} /$ electrolyte interface. The very nice agreement between experimental results and Mott-Schottky theory, shown in the Dewald's paper, together to a relatively simple interpretative model rendered very popular, through the years, the use of such an approach also in the study of semiconducting passive film/electrolyte junctions. However, in the case of passive films, the extreme thinness and the disordered or amorphous structure add further complications, to the possible interpretative models of differential capacitance data, but they have been usually neglected by assuming, as valid also for these systems, the theory of MottSchottky junctions in spite of the experimental evidence conflicting with the main assumptions underlying the use of simple $\mathrm{M}-\mathrm{S}$ theory [3]. According to this it is not surprising that, in spite of the numerous studies on passive-film/electrolyte interfaces, an unambiguous picture or a generalized acceptance of interpretative models is still lacking.

In recent papers [5, 16-19] we have suggested that the theory of amorphous semiconductor (a-SC) Schottky barrier [20-24] is able to explain in a very large range of electrode potential and ac frequencies both the EIS spectra as well as the behaviour of both component of admittance as a function of electrode potential of thin and thick films of semiconducting anodic oxide film grown on different metals $(\mathrm{Ti}, \mathrm{Nb}$, W). However the use of a rather complex equivalent circuit in EIS study as well the limited range of accessible frequencies and electrode potentials although confirmed, in our opinion, the validity of the theory of a-SC Schottky barrier hampered a more direct comparison of $\mathrm{M}-\mathrm{S}$ theory and a-SC Schottky barrier in the interpretation of the experimental results. In this work we present some results of a more detailed investigation on the semiconducting properties of amorphous thick $(\sim 159 \mathrm{~nm})$ anodic niobia grown on magnetron sputtered metal, aged under vacuum, and showing a semiconducting behaviour in a large range of frequency $(10 \mathrm{~Hz}-20 \mathrm{kHz})$ and electrode potential region (about $6 \mathrm{~V}$ ). Owing to the almost ideal behaviour of the aged $\alpha-\mathrm{Nb}_{2} \mathrm{O}_{5}$ /electrolyte junction a quite simple electrical equivalent circuit has been used to derive the two components of the differential admittance as a function of electrode potential and ac frequency which allowed to test both the a-SC Schottky barrier model and the traditional $\mathrm{M}-\mathrm{S}$ approach as for the frequency and potential dependence of the differential capacitance measurements. Such an investigation is aimed to explain some inconsistencies arising in the use of simple Mott-Schottky analysis to interpret the impedance behaviour of amorphous semiconducting (a-SC) passive films as well as to show that the theory of a-SC Schottky barrier provides a physically grounded explanation of usually observed experimental findings.

\section{EXPERIMENTAL}

Niobium films ( $300 \mathrm{~nm}$ thick) were magnetronsputtered on to glass substrate using $99.9 \%$ pure niobium target of $100 \mathrm{~mm}$ in diameter. The deposited niobium had a bcc structure with a [100] preferred orientation [25]. These films were anodized at a constant current density of $50 \mathrm{~A} \mathrm{~m}^{-2}$ in $0.1 \mathrm{~mol} \mathrm{dm}^{-3}$ ammonium pentaborate (ABE) electrolyte at $293 \mathrm{~K}$, the potential being kept constant for $1 \mathrm{~h}$ at $50 \mathrm{~V}$. After anodizing, specimens were heat treated in vacuum $\left(5 \times 10^{-6}-10^{-5}\right.$ Torr) at $523 \mathrm{~K}$ for $1 \mathrm{~h}$. A detailed study on the influence of thermal treatment in vacuum on morphological, compositional and electrical properties of anodic niobia films here investigated, has been reported in Refs. [25, 26]. For this work it is necessary to mention that, according to the Transmission Electron Micrograph of ultramicrotomed sections as well as to the Glow Discharge Optical Emission Spectroscopy (GDOES) analysis of the investigated film [26], the thickness of the aged $\mathrm{Nb}_{2} \mathrm{O}_{5}$ before and after thermal treatment was about $160 \mathrm{~nm}$. As reported in literature [26, 27, and, Refs. therein] some oxygen dissolution into the underlying niobium metal occurred during the annealing. Impedance spectra and differential admittance curves were recorded in $0.5 \mathrm{M} \mathrm{H}_{2} \mathrm{SO}_{4}$ solution by using a Parstat 2263 (PAR), connected to a computer for the data acquisition. For all the experiments, a Pt net having a very high surface area was used as counter electrode and a $\mathrm{Ag} / \mathrm{AgCl} / 3.5 \mathrm{M} \mathrm{Cl}^{-}$ (SSC) was employed as reference electrode.

\section{RESULTS AND DISCUSSION}

\subsection{Electrochemical Impedance Spectroscopy (EIS) and Differential Admittance (DA) Study}

EIS spectra of the aged $\mathrm{Nb}_{2} \mathrm{O}_{5}$ were recorded in $0.5 \mathrm{M} \mathrm{H}_{2} \mathrm{SO}_{4}$ in a wide range of electrode potential (-0.25-6.0 V vs. SSC). The EIS experimental data were validated using the Kramers-Kronig $(\mathrm{K}-\mathrm{K})$ transformation, as explained elsewhere [19, 28]. The $\mathrm{K}-\mathrm{K}$ transformed data and the experimentally acquired ones showed small discrepancies and the relative errors were always less than 3\% [19]. In Fig. 1 the Bode plot of the aged $\mathrm{Nb}_{2} \mathrm{O}_{5}$ in $0.5 \mathrm{M} \mathrm{H}_{2} \mathrm{SO}_{4}$ solution are reported at different potentials. The phase shift (Fig. 1b) shows that the behaviour of the aged $\mathrm{Nb}_{2} \mathrm{O}_{5}$ electrodes is capacitive at all the potentials, showing values near to $90^{\circ}$. At $-0.25 \mathrm{~V}$ vs. SSC the phase angle at low frequencies $(<1 \mathrm{~Hz})$ slightly decreases due to a side reaction with high charge transfer resistance. The 

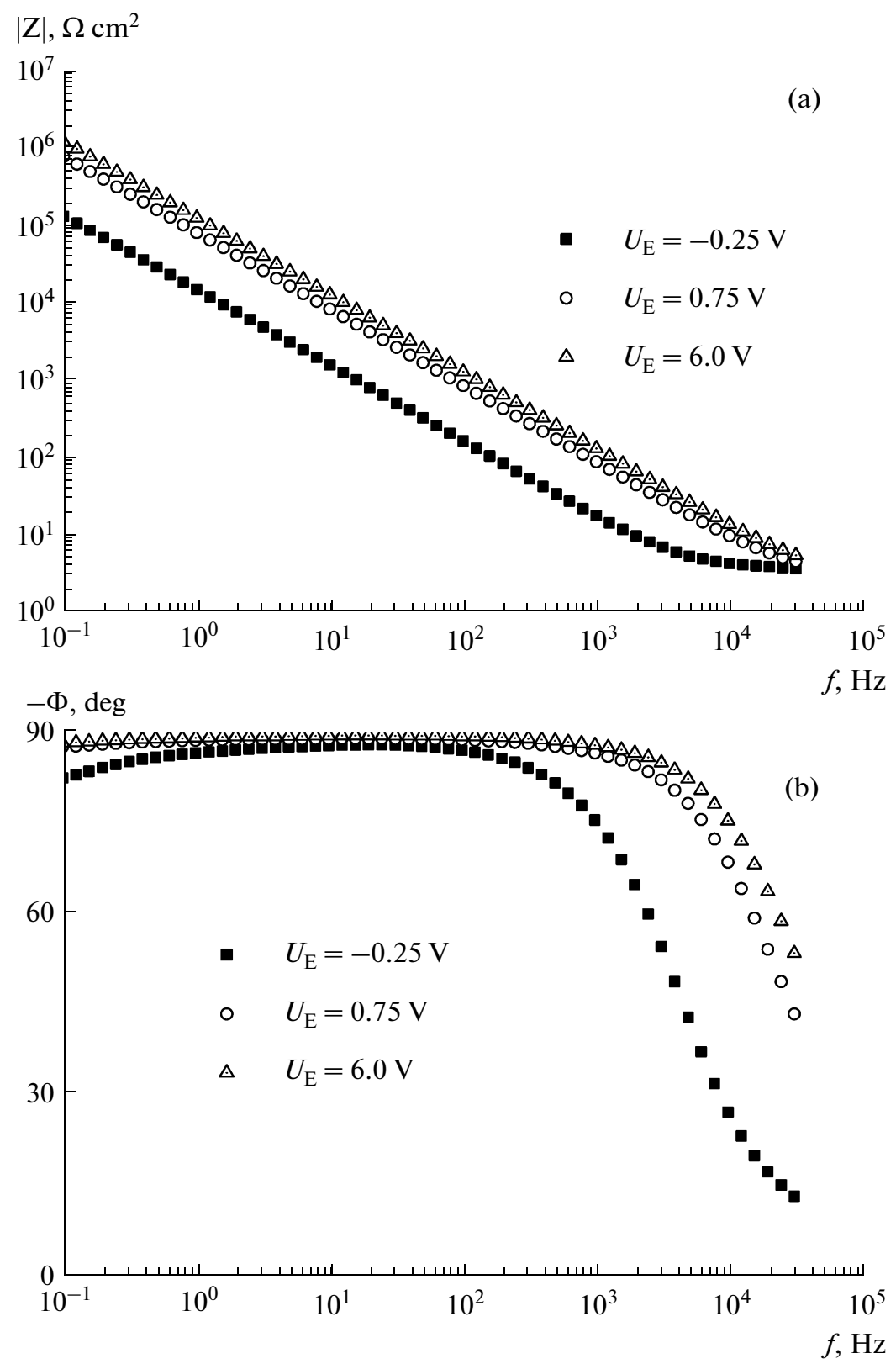

Fig. 1. Bode representation of the impedance data acquired at different polarization potentials (SSC) in $0.5 \mathrm{M} \mathrm{H}_{2} \mathrm{SO}_{4}$, relating to aged $50 \mathrm{~V}$ anodic films on $\mathrm{Nb}$ : (a) impedance magnitude and (b) phase angle.

absolute value of the impedance of the aged $\mathrm{Nb}_{2} \mathrm{O}_{5}$ (Fig. 1a) increases by increasing the polarization potentials. This behaviour is in agreement with the semiconducting nature of the electrode.

Owing to the ideally polarizable behaviour of the investigated interface the electrical equivalent circuit used in fitting the EIS spectra and in correcting the DA curves (see Fig. 2) contains, apart the series resistance $\left(2.83 \Omega \mathrm{cm}^{2}\right)$ and the capacitance of the Helmholtz double layer $\left(20 \mu \mathrm{F} \mathrm{cm} \mathrm{cm}^{-2}\right)$, the contribution of the space charge layer of semiconducting niobia oxide (admittance $Y_{\mathrm{SC}}$, or impedance $Z_{\mathrm{SC}}$ ). In Fig. 3 the dif- ferential admittance curves of the aged $\mathrm{Nb}_{2} \mathrm{O}_{5}$, obtained by correcting the measured capacitance according to the equivalent electric circuit of Fig. 2, are reported as the parallel capacitance and conductance components at different frequencies. As a general rule, we observe that, at fixed polarization potential, the capacitance decreases by increasing the frequency and, at fixed frequency, decreases by increasing the polarization potential. Such a behaviour has been frequently observed for semiconducting passive films grown on a number of valve metal ([3] and refs. therein) and very recently it has been 
observed also on amorphous $\mathrm{TiO}_{2}$ film grown on different single grains of pure (99.9\%) titanium [29]. The frequency dependence of the capacitance is reflected in Mott-Schottky plots usually showing both donor density and flat band potential values frequency dependent [4, 29-32]. When this occurs for crystalline semiconductor/electrolyte junctions several physical explanations have been suggested in the literature as possible source of this dependence [33-36] like:

(a) deep lying donors

(b) surface states

(c) surface roughness

(d) ionic charges movement (or defect migration)

(e) frequency dependent dielectric constant

On the other hand we have shown [5, 16-18, 37] that frequency dependent differential admittance values are theoretically expected for amorphous semiconductor passive film/electrolyte junction in agreement with the theory of amorphous semiconductor Schottky barriers. However, in many works dealing with passive films ([3] and Refs. therein), the traditional approach based on the use of a simple MottSchottky analysis of the differential capacitance vs. potential plots is still largely employed without any attempt to verify if the hypothesis underlying the $\mathrm{M}-\mathrm{S}$ theory are compatible with the experimental findings. In order to clarify such aspects we will discuss the differential capacitance data of Fig. 3 according to the $\mathrm{M}-\mathrm{S}$ theory of crystalline semiconductors and we will compare the results obtained by the $\mathrm{M}-\mathrm{S}$ analysis with the results based on the theory of amorphous Schottky barrier [19, 28].

In Fig. 4 we report the $C_{\mathrm{SC}}^{-2}$ vs. $U_{\mathrm{E}}$ plots of the aged amorphous niobia at different ac frequencies and in a very large range of electrode potential (about $6 \mathrm{~V}$ ). In the frequency range exploited in figure $(10 \mathrm{~Hz}-1 \mathrm{kHz})$ the $\mathrm{M}-\mathrm{S}$ plots display a linear behaviour in a short range of electrode potential values, $U_{\mathrm{E}}$, comprised between $-0.2 \mathrm{~V}$ vs. SSC and $0.1 \mathrm{~V}$ vs. SSC where donor density, $N_{\mathrm{d}, 1}$, steadily decreases with increasing ac frequency. Moreover such a linear region is also shortened with increasing ac frequency. This low band bending $\mathrm{M}-\mathrm{S}$ region is followed, at higher electrode potential values $U_{\mathrm{E}}>2 \mathrm{~V}$ vs. SSC, by a second linear $\mathrm{M}-\mathrm{S}$ region having a lower, almost constant at any frequency, slope covering a much larger interval of electrode potential values (nearly $4 \mathrm{~V}$ ) (see Fig. 5). From the low band bending region a flat band potential value, slightly changing with the frequency, and equal to $-0.3 \pm 0.025 \mathrm{~V}$ vs. SSC has been measured by extrapolating the $\mathrm{M}-\mathrm{S}$ plots in a variable potential region as observed in Fig. 4. On the other hand from the high band bending region an almost constant donor density, $N_{\mathrm{d}, 2}$, equal to about $5 \times 10^{19} \mathrm{~cm}^{-3}$ can be derived from the measured slope and by assuming for

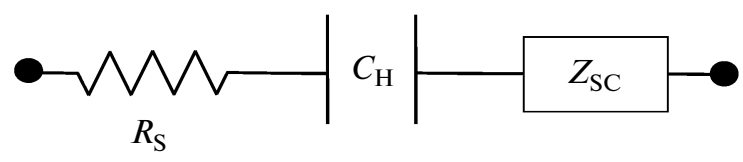

Fig. 2. Equivalent electrical circuit employed to simulate the impedance of the metal/oxide/electrolyte interface (adapted from Ref. [19]).

amorphous niobia a value of relative dielectric constant $\varepsilon_{\mathrm{ox}}=53$ [28]. More details on the experimentally measured parameters, in both low and high band bending regime, are reported in Table 1. An estimate of the space charge region width, at the highest frequency here investigated $(1 \mathrm{kHz})$ and at the largest anodic potential value $(6 \mathrm{~V} / \mathrm{SSC})$, gives a figure of about $33 \mathrm{~nm}$ well below the measured niobia oxide film above reported $(160 \mathrm{~nm})$.

The $\mathrm{M}-\mathrm{S}$ behaviour described above has been reported in many different works dealing with crystalline or amorphous materials and in absence of surface states contribution to the measured capacitance such behaviour has been attributed to the existence of a second donor level deeply lying in energy well below the conduction band edge. The other possible sources of frequency dependence can be discarded in our case owing to the fact that the magnetron sputtered sample of niobium presents a negligible surface roughness and it has been anodized at a final potential $\left(V_{\mathrm{f}}=50 \mathrm{~V}\right.$ vs. NHE) well above the electrode potential range exploited in the $\mathrm{M}-\mathrm{S}$ plots, so that any ionic current can be assumed as negligible. On the other hand it does not appear reasonable to hypothesize a frequency-dependent dielectric constant for niobia in the range of frequency exploited in our $\mathrm{M}-\mathrm{S}$ analysis of experimental data.

In order to test the deep lying donor hypothesis we carried out a detailed numerical calculation of the Mott-Schottky plots expected by assuming initially a crystalline semiconducting niobia and the presence of

Table 1. Flat band potential and donor concentration obtained from the linear regression of the low potential region $(<0.1 \mathrm{~V} / \mathrm{SSC})$ in Fig. $4\left(U_{\mathrm{fb}, 1}\right.$ and $\left.N_{\mathrm{d}, 1}\right)$ and from the linear regression of the high potential region $(>2 \mathrm{~V} / \mathrm{SSC})$ in Fig. 5 $\left(U_{\mathrm{fb}, 2}\right.$ and $\left.N_{\mathrm{d}, 2}\right)$. Potentials are given with respect to SSC

\begin{tabular}{c|c|c|c|c}
\hline$f, \mathrm{~Hz}$ & $U_{\mathrm{fb}, 1}, \mathrm{~V}$ & $N_{\mathrm{d}, 1}, \mathrm{~cm}^{-3}$ & $U_{\mathrm{fb}, 2}, \mathrm{~V}$ & $N_{\mathrm{d}, 2}, \mathrm{~cm}^{-3}$ \\
\hline 1000 & -0.306 & $5.7 \times 10^{18}$ & -3.55 & $5.1 \times 10^{19}$ \\
100 & -0.301 & $8.2 \times 10^{18}$ & -3.13 & $5.4 \times 10^{19}$ \\
10 & -0.296 & $1.3 \times 10^{19}$ & -2.54 & $5.5 . \times 10^{19}$ \\
\hline
\end{tabular}

No. 112010 

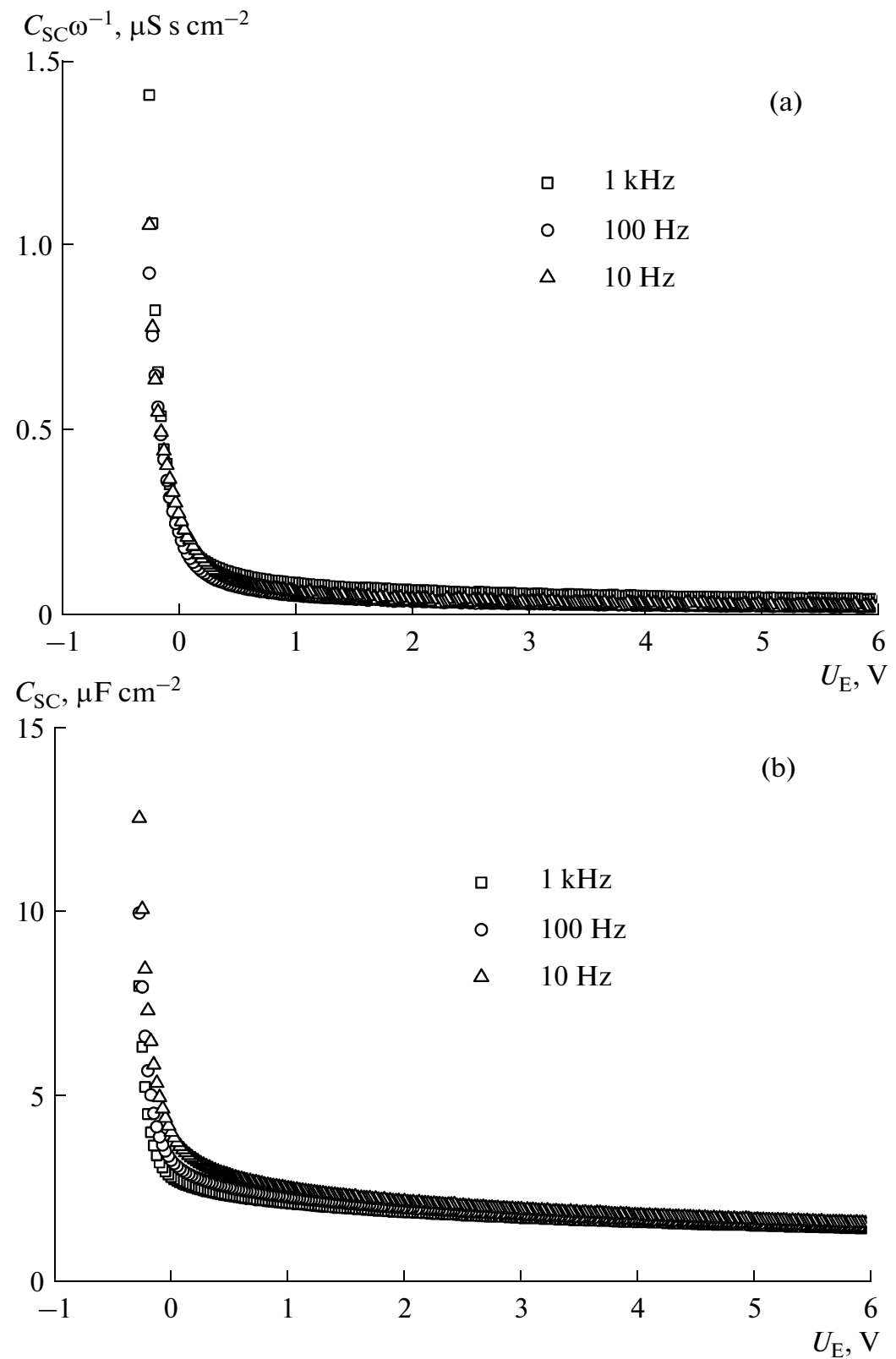

Fig. 3. Corrected differential admittance curves acquired at different frequencies in $0.5 \mathrm{M} \mathrm{H}_{2} \mathrm{SO}_{4}$, relating to aged $50 \mathrm{~V}$ anodic films on Nb: (a) $G_{\mathrm{SC}} \omega^{-1}$ and (b) $C_{\mathrm{SC}}$.

multiple donor levels located at different energies from the conduction band edge of semiconductor. The experimental findings will be compared with the results of this calculation as well as with the results of a fitting carried out on the basis of the equations derived from the amorphous semiconductor Schottky barrier theory.

\subsection{Simulation and Mott-Schottky Analysis}

In this case we will use the original treatment of Losee [38] to carry out a numerical simulation of the impedance behaviour of a crystalline semiconductor
(c-SC) in presence of a constant donor density (shallow donor level) and a deep donor level located at a fixed energy distance, $E_{\mathrm{T}}$, from the conduction band edge of the c-SC. The differential capacitance of the semiconductor/electrolyte junction is obtained by starting from the Poisson equation for small ac signals [38]:

$$
\frac{\partial^{2} \varphi}{\partial x}=\frac{F(\psi, \omega)}{\varepsilon} \varphi,
$$

where $\varphi$ is the ac component of SC band bending at a point $x$ in the semiconductor, $\varepsilon$ the dielectric constant of the semiconductor, $F$ is the first order coef- 


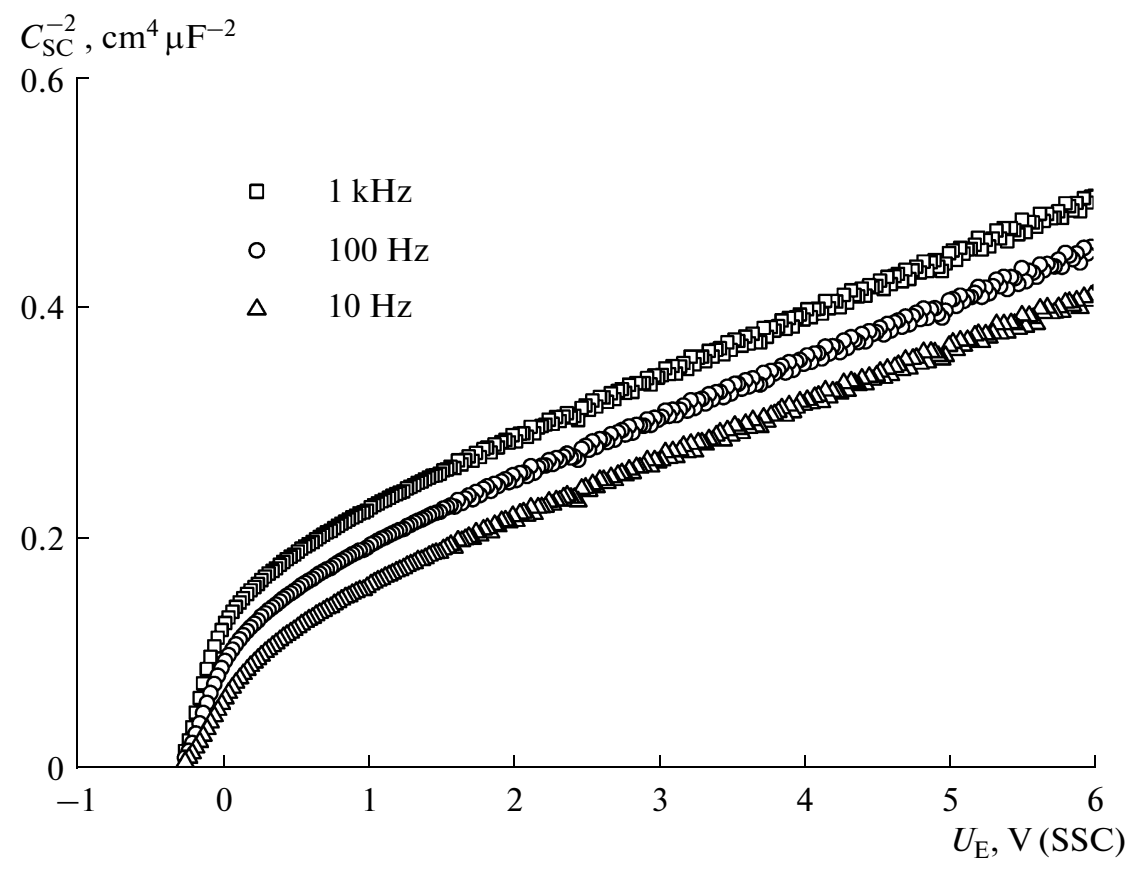

Fig. 4. Mott-Schottky plot at different frequencies in $0.5 \mathrm{M} \mathrm{H}_{2} \mathrm{SO}_{4}$, relating to aged $50 \mathrm{~V}$ anodic films on $\mathrm{Nb}$.

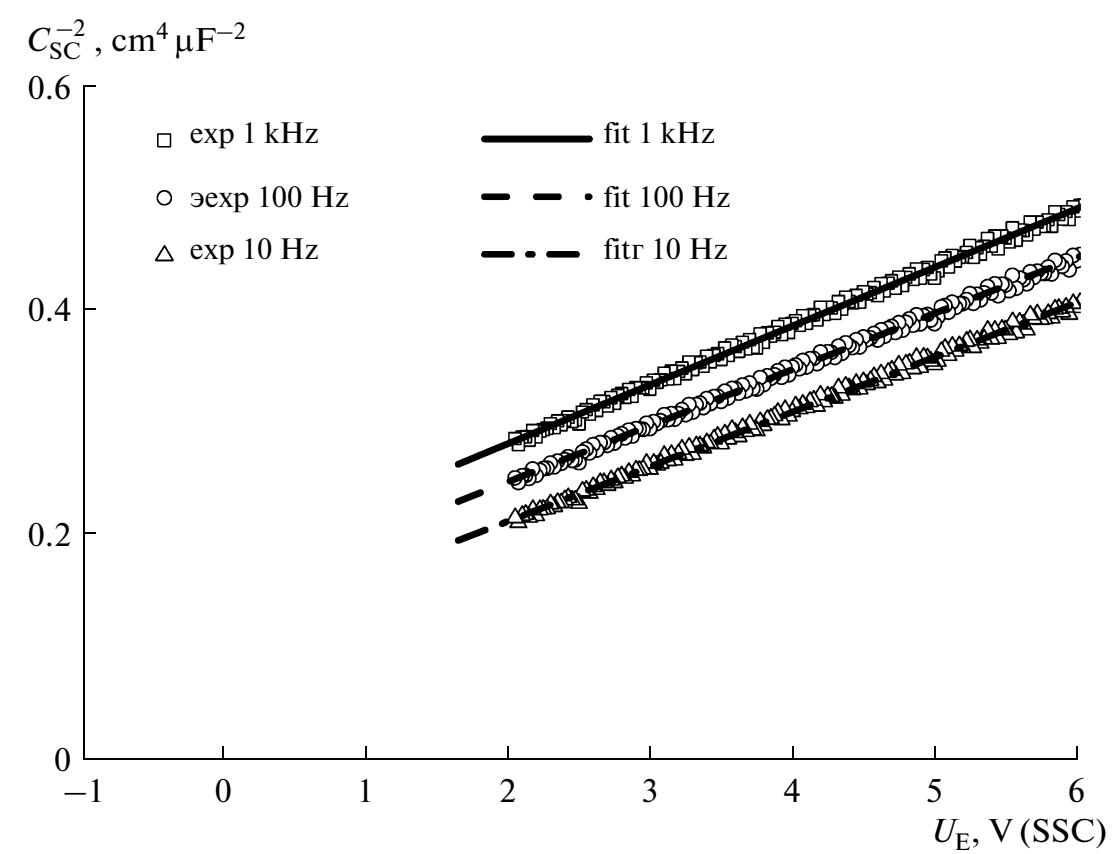

Fig. 5. Mott-Schottky plot and linear regression for $U_{\mathrm{E}}>2 \mathrm{~V}$ vs. SSC at different frequencies in $0.5 \mathrm{M} \mathrm{H}_{2} \mathrm{SO}_{4}$, relating to aged $50 \mathrm{~V}$ anodic films on $\mathrm{Nb}$.

ficient of $\varphi$ in the expansion of the ac component of density of charge $\left(\rho_{\mathrm{ac}}(\psi, \omega, \varphi)=F(\psi, \omega) \varphi\right)$. As evidenced by symbols, $F$ is a function of angular frequency, to, and band bending $\psi(x)$ inside the semiconductor. It has been shown in Ref. [38] that Eq. (1) can be rewritten after a suitable change of variables as:

$$
\frac{\rho(\psi)}{\varepsilon} \frac{\partial \varphi}{\partial \psi}+H(\psi) \frac{\partial^{2} \varphi}{\partial \psi^{2}}=\frac{F(\psi, \omega)}{\varepsilon} \varphi,
$$

where $\rho$ is now the static volumetric charge density

No. $11 \quad 2010$ 
and $H(\psi)$ is the square of the electric field. The Losee's equation (2) can be simplified with a careful choice of a new variable by defining it as:

$$
W(\psi, \omega)=\varphi \frac{\partial \psi}{\partial \varphi} .
$$

According to this the second order differential equation (2) can be transformed in a first order differential equation:

$$
\begin{gathered}
\frac{d W(\psi, \omega)}{d \psi} \\
=1+\frac{\rho(\psi)}{\varepsilon H(\psi)} W(\psi, \omega)-\frac{F(\psi, \omega)}{\varepsilon H(\psi)} W^{2}(\psi, \omega) .
\end{gathered}
$$

$W$ has the dimension of an electrical potential and it is related to the impedance of the space charge region through the relationship [38]:

$$
Z_{\mathrm{SC}}\left(\psi_{\mathrm{S}}, \omega\right)=\frac{W_{\mathrm{S}}}{i \omega \varepsilon H_{\mathrm{S}}^{0.5}},
$$

where $W_{\mathrm{S}}$ and $H_{\mathrm{S}}$ are the value of $W$ and $H$ at the $\mathrm{SC} / \mathrm{E} 1$ the interface, respectively. $W_{\mathrm{S}}$ is now obtained by integration of a first order differential equation (4). More details on the mathematical treatment can be found in the original Loose's paper [38]. The mathematical expressions of $\rho, H$, and $F$ depend on the nature of the semiconductor so that the previous equations (4)-(5) can be used indifferently for amorphous or crystalline materials once the correct expressions are used for the total charge density inside the space charge region of the semiconductor. For non-degenerated semiconductor with two donor levels, one completely ionized at the flat band potential (shallow donor level), and the second one not ionized at the flat band potential (deep donor level) the expressions of $\rho, H$, and $F$ are given by:

$$
\begin{gathered}
\rho_{\mathrm{SL}}(\psi)=|\mathrm{e}| N_{\mathrm{C}} \exp \left(-\frac{\Delta E_{\mathrm{F}}}{k_{\mathrm{B}} T}\right)\left[1-\exp \left(-\frac{|\mathrm{e}| \psi}{k_{\mathrm{B}} T}\right)\right], \\
\rho_{\mathrm{DL}}(\psi)=\sum_{i}|\mathrm{e}| N_{\mathrm{T}, i}\left[\frac{1}{1+\exp \left(-\frac{E_{\mathrm{T}, i}+|\mathrm{e}| \psi-E_{\mathrm{F}}}{k_{\mathrm{B}} T}\right)}\right. \\
\left.-\frac{1}{1+\exp \left(-\frac{E_{\mathrm{T}, i}-E_{\mathrm{F}}}{k_{\mathrm{B}} T}\right)}\right] \\
\rho(\psi)=\rho_{\mathrm{SL}}(\psi)+\rho_{\mathrm{DL}}(\psi), \\
H(\psi)=\frac{2}{\varepsilon} \int_{0}^{\psi} \rho\left(\psi^{\prime}\right) d \psi^{\prime},
\end{gathered}
$$

$$
\begin{gathered}
F(\psi, \omega)=\frac{d \rho_{\mathrm{SL}}}{d \psi}+\frac{1}{1+i \omega \tau(\psi)} \frac{d \rho_{\mathrm{DL}}}{d \psi}, \\
\tau(\psi)=\tau_{0} \exp \left(\frac{\Delta E_{\mathrm{F}}+|\mathrm{e}| \psi}{k_{\mathrm{B}} T}\right),
\end{gathered}
$$

where $N_{\mathrm{C}}$ is the effective number of states at the bottom of the conduction band, $N_{\mathrm{T}, i}$ the concentration of the $i$-th donor level, $E_{\mathrm{T}, i}$ the energy location of the $i$-th donor level, $E_{\mathrm{F}}$ the Fermi level at the flat band, $\tau$ the capture-emission time constant of the donor levels, $\omega$ the angular frequency, $k_{\mathrm{B}}$ the Boltzmann constant, $T$ the absolute temperature, $\tau_{0}$ a constant depending on the material (values between $10^{-10}$ and $10^{-14} \mathrm{~s}$ are usually assumed), and $\Delta E_{\mathrm{F}}$ represents the distance between the conduction band edge and the Fermi level in the bulk (n-type semiconductors). The location of the Fermi level is obtained imposing the electroneutrality condition at the flat band potential:

$$
\begin{gathered}
\sum_{i}|\mathrm{e}| N_{\mathrm{T}, i}\left[\frac{1}{1+\exp \left(-\frac{E_{\mathrm{T}, i}-E_{\mathrm{C}}+\Delta E_{\mathrm{F}}}{k_{\mathrm{B}} T}\right)}\right] \\
-|\mathrm{e}| N_{\mathrm{C}} \exp \left(-\frac{\Delta E_{\mathrm{F}}}{k_{\mathrm{B}} T}\right)=0 .
\end{gathered}
$$

Once the electronic properties of the semiconductor are fixed, the value $\Delta E_{\mathrm{F}}$ can be obtained from Eq. (7). Even in absence of shallow donor levels, the concentration of holes in Eq. (7) can be neglected for high band gap (mobility gap) semiconductors, because the intrinsic concentration of charge carriers, $n_{\mathrm{i}}$, is extremely low (for $E_{\mathrm{g}}=3.45 \mathrm{eV}, N_{\mathrm{C}}=N_{\mathrm{V}}=3 \times 10^{20} \mathrm{~cm}^{-3}$, one obtains $n_{\mathrm{i}}=5.5 \times 10^{-9} \mathrm{~cm}^{-3}$ ).

In case of a single donor level completely ionized, the expressions $(6 a)-(6 b)$ are given by:

$$
\begin{gathered}
\rho_{\mathrm{SL}}(\psi)=|\mathrm{e}| N_{\mathrm{D}}\left[1-\exp \left(-\frac{|\mathrm{e}| \psi}{k_{\mathrm{B}} T}\right)\right], \\
\rho_{\mathrm{DL}}(\psi) \approx 0,
\end{gathered}
$$

and the Losee's equation (4) can be written as:

$$
\begin{gathered}
\frac{d W}{d \psi}=1+\frac{\left[1-\exp \left(-\frac{\mathrm{e} \mid \psi}{k_{\mathrm{B}} T}\right)\right]}{2\left\{\psi-\frac{k_{\mathrm{B}} T}{|\mathrm{e}|}\left[1-\exp \left(-\frac{\mathrm{e} \mid \psi}{k_{\mathrm{B}} T}\right)\right]\right\}} W \\
-\frac{\frac{|\mathrm{e}|}{k_{\mathrm{B}} T} \exp \left(-\frac{|\mathrm{e}| \psi}{k_{\mathrm{B}} T}\right)}{2\left\{\psi-\frac{k_{\mathrm{B}} T}{|\mathrm{e}|}\left[1-\exp \left(-\frac{|\mathrm{e}| \psi}{k_{\mathrm{B}} T}\right)\right]\right\}} W^{2} .
\end{gathered}
$$


The analytical solution of Eq. (9) is:

$$
W(\psi)=\frac{2\left\{\psi-\frac{k_{\mathrm{B}} T}{|\mathrm{e}|}\left[1-\exp \left(-\frac{\mathrm{e} \mid \psi}{k_{\mathrm{B}} T}\right)\right]\right\}}{\left[1-\exp \left(-\frac{|\mathrm{e}| \psi}{k_{\mathrm{B}} T}\right)\right]} .
$$

Substitution of Eq. (6d), (8a), (8b), (9) in the expression (5) for the impedance of the junction will give:

$$
\begin{gathered}
Z_{\mathrm{SC}}\left(\psi_{\mathrm{S}}, \omega\right)=\frac{1}{\mathrm{i} \omega} \sqrt{\frac{2}{\varepsilon|\mathrm{e}| N_{\mathrm{D}}}} \\
\times \frac{\left\{\psi_{\mathrm{S}}-\frac{k_{\mathrm{B}} T}{|\mathrm{e}|}\left[1-\exp \left(-\frac{\mathrm{e} \mid \psi_{\mathrm{S}}}{k_{\mathrm{B}} T}\right)\right]\right\}^{\frac{1}{2}}}{\left[1-\exp \left(-\frac{|\mathrm{e}| \psi_{\mathrm{S}}}{k_{\mathrm{B}} T}\right)\right]}
\end{gathered}
$$

or equivalently:

$$
\begin{gathered}
\frac{1}{C_{\mathrm{SC}}\left(\psi_{\mathrm{S}}, \omega\right)} \\
=\sqrt{\frac{2}{\varepsilon|\mathrm{e}| N_{\mathrm{D}}}} \frac{\left\{\psi_{\mathrm{S}}-\frac{k_{\mathrm{B}} T}{|\mathrm{e}|}\left[1-\exp \left(-\frac{|\mathrm{e}| \psi_{\mathrm{S}}}{k_{\mathrm{B}} T}\right)\right]\right\}^{\frac{1}{2}}}{\left[1-\exp \left(-\frac{\mathrm{e} \mid \psi_{\mathrm{S}}}{k_{\mathrm{B}} T}\right)\right]},
\end{gathered}
$$

with $\psi_{\mathrm{S}}=U_{\mathrm{E}}-U_{\mathrm{FB}}$. Equation (12) coincides with the expression reported in Ref. [12] (Eq. (11)) under the hypothesis of completely ionized donors in the bulk of semiconductor, and the square of Eq. (12) at sufficiently high anodic polarization, $\left(|\mathrm{e}| \psi_{\mathrm{S}}>3 k_{\mathrm{B}} T\right)$, gives the well known frequency-independent Mott-Schottky approximation for $n$-type SC:

$$
\frac{1}{C_{\mathrm{SC}}^{2}\left(\psi_{\mathrm{S}}, \omega\right)}=\frac{2}{\varepsilon|\mathrm{e}| N_{\mathrm{D}}}\left\{\psi_{\mathrm{S}}-\frac{k_{\mathrm{B}} T}{|\mathrm{e}|}\right\} .
$$

For the general case, the value of $W_{\mathrm{S}}$ (see Eq. (9)) has been numerically evaluated by using the Runge-Kutta method. In particular, it can be observed that, as starting point, $W(0)=0$, but $d W / d \psi$ gives an undetermined form $(0 / 0)$ numerically unmanageable. According to this we can assume, near $\psi=0 W=K \psi$ (it respects the boundary conditions) and evaluate $d W / d \psi$ from the Taylor approximation of the functions $H, \rho$, and $F$ near the point $\psi=0$. The following expression for $K$ can be obtained:

$$
\begin{gathered}
K=\left.\frac{d W}{d \psi}\right|_{\psi=0} \\
=\left[\frac{\left.\frac{d \rho_{\mathrm{SL}}}{d \psi}\right|_{\psi=0}+\left.\frac{d \rho_{\mathrm{DL}}}{d \psi}\right|_{\psi=0}}{\left.\frac{1}{d \rho_{\mathrm{SL}}}\right|_{\psi=0}+\left.\frac{1}{1+\mathrm{i} \omega \tau(\psi=0)} \frac{d \rho_{\mathrm{DL}}}{d \psi}\right|_{\psi=0}}\right]^{1 / 2}
\end{gathered}
$$

and expression (14) can be used to start the RungeKutta integration. The mathematical treatment, above reported, is valid for any kind of semiconductor and contains the simple Mott-Schottky model as a limiting case of a non-degenerated crystalline semiconductor with a single donor level fully ionized $\left(N_{\mathrm{T}}=0\right)$ at room temperature.

At first, we will try to model the experimental $\mathrm{M}-\mathrm{S}$ data in Fig. 4 by assuming that a crystalline semiconductor with two donor levels, a shallow one $\left(E_{\mathrm{C}}-E_{\mathrm{T}, 1}<k_{\mathrm{B}} T\right)$ and a deep one, is able to reproduce the data. Owing to the frequency dependent slope observed at low band bending we decided to use as starting point for the simulation of experimental curves the values of $U_{\mathrm{fb}}$ and donor density derived from the $\mathrm{M}-\mathrm{S}$ plot obtained at the intermediate frequency of $100 \mathrm{~Hz}$.

According to this, in the low band bending region, the following values were derived: $U_{\mathrm{fb}}=-0.3 \mathrm{~V}$ vs. $\mathrm{SSC} ; N_{\mathrm{T}, 1}=8.2 \times 10^{18} \mathrm{~cm}^{-3}, \Delta E_{\mathrm{F}} \approx 93.3 \mathrm{meV}$ (a value of $3 \times 10^{20} \mathrm{~cm}^{-3}$ for $N_{\mathrm{C}}$ was assumed, see Ref. [3]); whilst from the high band bending region we obtain the concentration of the deep donor level: $N_{\mathrm{T}, 2}=N_{\mathrm{d}, 2}-N_{\mathrm{d}, 1}=$ $4.6 \times 10^{19} \mathrm{~cm}^{-3}$. The only free parameter for the simulation of results remains the energy distance of the deep donor level from the conduction band, $E_{\mathrm{C}}-E_{\mathrm{T}, 2}$. The value of $E_{\mathrm{C}}-E_{\mathrm{T}, 2}$ is somehow correlated to the potential at which the Mott-Schottky plot deviates from linearity.

According to this in Fig. 6 we carried out the fitting of the experimental Mott-Schottky curves (see Fig. 4) by assuming $E_{\mathrm{C}}-E_{\mathrm{T}, 2}=24 k_{\mathrm{B}} T$ which posed the deep donor level at around $0.520 \mathrm{eV}$ below the Fermi level which coincides with flat band potential in the electrochemical scale above reported $(-0.3 \mathrm{~V}$ vs. SSC). As expected, for the low band bending region, the slope remains constant at all frequencies, at variance with the experimental observation, but with increasing potential as soon $E_{\mathrm{F}}$ reach the $E_{\mathrm{T}, 2}$ level, the effect of frequency is quite strong and rather neglected in older theoretical treatments dealing with disordered passive films [39]. In fact a large difference is appearing now in $\mathrm{M}-\mathrm{S}$ plots as a function of ac frequency with the lower frequencies $(10$ and $100 \mathrm{~Hz})$ simulating curves showing a maximum followed by a minimum whilst the plot at $1 \mathrm{kHz}$ displays a monotonic curvilinear behaviour. Usually the experimental behaviour is analogous to that displayed in Fig. 6 by the high fre- 


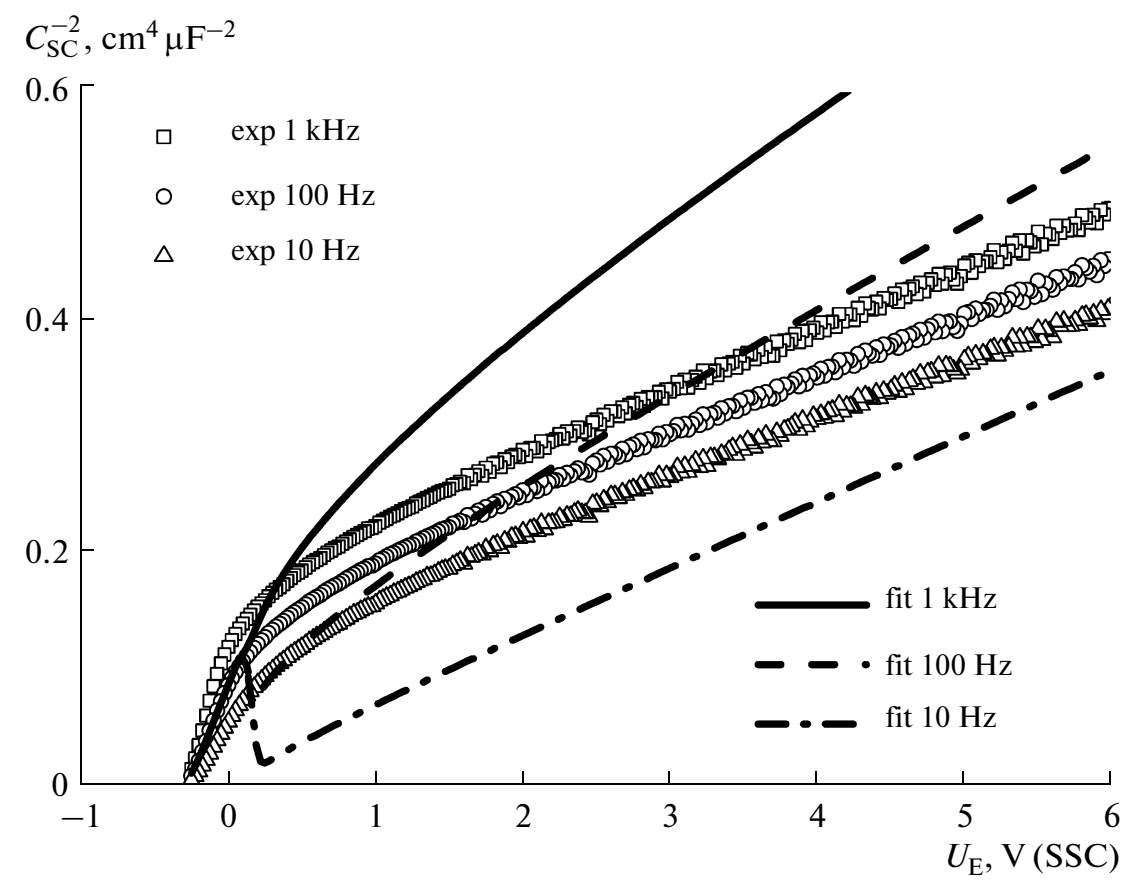

Fig. 6. Mott-Schottky plot and fitting curves at different frequencies in $0.5 \mathrm{M} \mathrm{H}_{2} \mathrm{SO}_{4}$, relating to aged $50 \mathrm{~V}$ anodic films on $\mathrm{Nb}$. The parameters of the fitting curves are $U_{\mathrm{fb}}=-0.3 \mathrm{Vvs}$. SSC; $N_{\mathrm{T}, 1}=8.2 \times 10^{18} \mathrm{~cm}^{-3} ; E_{\mathrm{C}}-E_{\mathrm{T}, 1}=0.5 k_{\mathrm{B}} T ; N_{\mathrm{T}, 2}=4.6 \times 10^{19} \mathrm{~cm}^{-3}$, $E_{\mathrm{C}}-E_{\mathrm{T}, 2}=24 k_{\mathrm{B}} T .\left(\Delta E_{\mathrm{F}} \approx 93.3 \mathrm{meV}\right)$.

quency $(1 \mathrm{kHz})$ plot. However it is worth to mention that at lower frequencies the simulating curves parallel the theoretical treatment reported in Ref. [40] which does not take into account the dynamic response of deep lying donor. This effect is due to the fact that when the ac frequency is sufficiently low (and the band bending sufficiently high) the deep donor level is partially ionized and the electrons therein are able to follow the ac signal. In these conditions the maximum/minimum appears in the Mott-Schottky plot as foreseen by the zero frequency approach reported in Ref. [40]. The difference between the maximum and the minimum depends on the number of deep donor able to follow the signal; higher is the concentration, stronger the difference. We like to point out, also, that at high band bending the simulated curves are not parallel to the experimental data and neither to each other (once again at variance with the experimental data) so that the apparent donor density derived in this region do not coincide with the value used to derive the theoretical curves. From the simulation reported in Fig. 6, it becomes clear that the change in the slope of the Mott-Schottky curves with frequency are systematic and depend from the presence of partially ionized deep donor levels. Based on this observation and with the aim to reproduce a frequency dependent $\mathrm{M}-\mathrm{S}$ plot also in the low band bending region we exploited a second model with two deep donor level $\left(E_{\mathrm{C}}-E_{\mathrm{T}, \mathrm{i}}>10 k_{\mathrm{B}} T\right)$.

In Figs. 7-9 we report the fitting of the MottSchottky curves for different values of $\left(E_{\mathrm{C}}-E_{\mathrm{T}, 1}\right)$ with the other parameters $\left(U_{\mathrm{fb}}, N_{\mathrm{d} 1}, N_{\mathrm{d} 2}, E_{\mathrm{T}, 2}\right)$ adjusted to obtain the best fitting of the $1 \mathrm{kHz}$ Mott-Schottky curve. $\Delta E_{\mathrm{F}}$ was evaluated from Eq. (7) and it is a function of $E_{\mathrm{C}}-E_{\mathrm{T}, 1}$ but practically independent from $E_{\mathrm{C}}-E_{\mathrm{T}, 2}$. As a general finding of the simulation procedure we observe that it exists a polarization potential, in the low band bending region, below which the three curves merge (see inset in Fig. 9). The merging potential value depends on the value of $\Delta E_{\mathrm{F}}$ and such a feature, in the simulating curves, occurs when the Fermi level crosses the first donor level higher lying in energy. After merging, at still lower electrode potentials, the simulated $C_{\mathrm{SC}}^{-2}$ vs. $U_{\mathrm{E}}$ curves display, at any frequency, a sudden increase at variance with the experimental data. The decrease is steeper the higher is the difference $E_{\mathrm{C}}-E_{\mathrm{T}, 1}$. At electrode potential more anodic than the merging potential value the $\mathrm{M}-\mathrm{S}$ plots display different slopes, in the low band bending region, similar to that observed in the experimental curves. Both the slope in the low band bending region as well as the best fitting at higher electrode potential values are strongly depending from the exact location in energy of the first donor level as evidenced by the large improvement in the fitting process by an increase of the $E_{\mathrm{T}, 1}$ of $4 k_{\mathrm{B}} T$. A further increase in the $E_{\mathrm{T}, 1}$ energy level, by keeping constant all the other fitting parameters (see Table 2), worsened very much the agreement between the theoretical and experimental data. By comparison of the experimental data in Table 1 derived from the use of $\mathrm{M}-\mathrm{S}$ analysis with the fitting parameters reported in Table 2 for the best fitting 


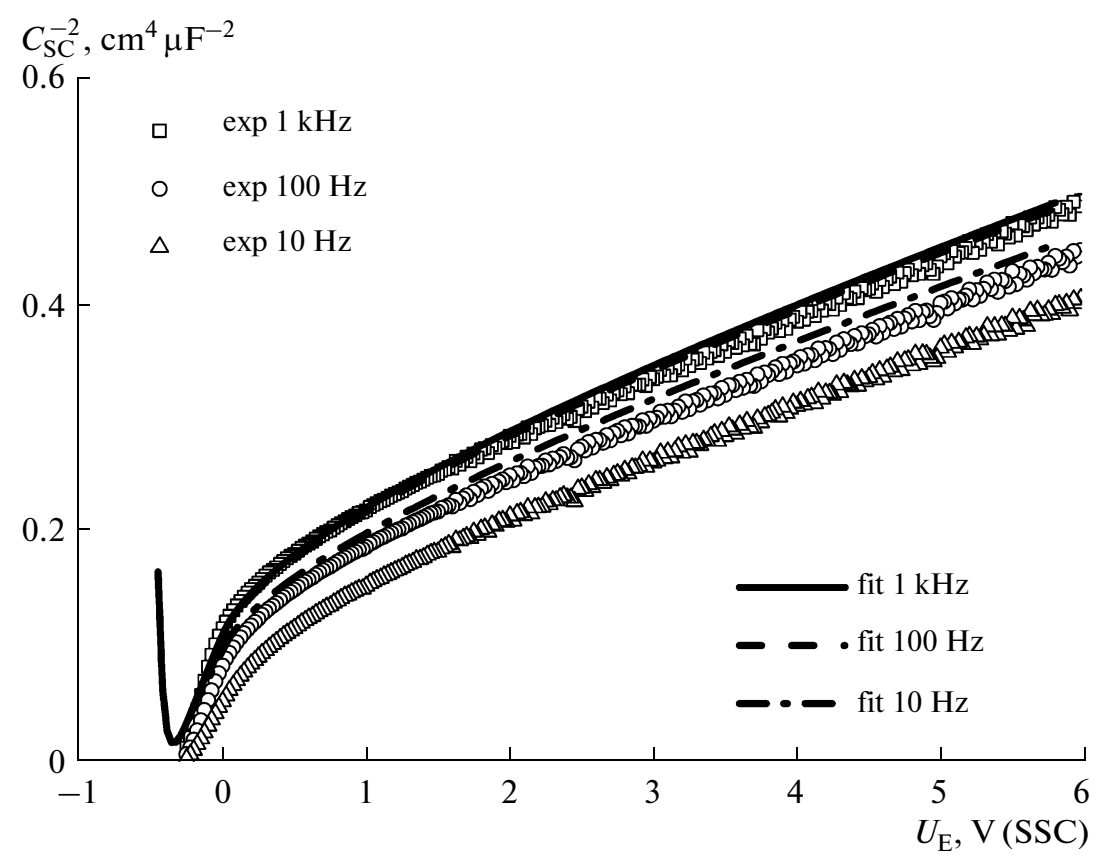

Fig. 7. Mott-Schottky plot and fitting curves at different frequencies in $0.5 \mathrm{M} \mathrm{H}_{2} \mathrm{SO}_{4}$, relating to aged $50 \mathrm{~V}$ anodic films on $\mathrm{Nb}$. The parameters of the fitting curves are: $U_{\mathrm{fb}}=-0.5 \mathrm{Vvs}$. SSC; $N_{\mathrm{T}, 1}=8.5 \times 10^{18} \mathrm{~cm}^{-3}, E_{\mathrm{C}}-E_{\mathrm{T}, 1}=14 k_{\mathrm{B}} T, N_{\mathrm{T}, 2}=1.0 \times 10^{20} \mathrm{~cm}^{-3}$, $E_{\mathrm{C}}-E_{\mathrm{T}, 2}=29 k_{\mathrm{B}} T .\left(\Delta E_{\mathrm{F}} \approx 226 \mathrm{meV}\right)$.

curves displayed in Fig. 9 it is possible to draw some preliminary conclusions on the nature of the information provided by the use of a simple $\mathrm{M}-\mathrm{S}$ approach in the study of this system.

In absence of any surface state contribution to the measured capacitance, the real flat band potential necessary to fit the experimental data, also for $\mathrm{M}-\mathrm{S}$ plots converging to the same point in the potential axis, is appreciably (about $0.2 \mathrm{~V}$ ) more cathodic than that derived from the $\mathrm{M}-\mathrm{S}$ plots. This finding does not support the idea that frequency dependent $\mathrm{M}-\mathrm{S}$ plots converging to the same electrode potential can be, always, used to locate the real flat band potential [33] in c-SC/electrolyte junction (or semiconducting anodic film/electrolyte junction).

On the other hand the behaviour of $\mathrm{M}-\mathrm{S}$ plots at high band bending displaying an almost frequency independent behaviour does not provide generally the right donor density underlying the simple $\mathrm{M}-\mathrm{S}$ analysis of the crystalline semiconductor/electrolyte interface. In fact from the data of Table 1 and Table 2 it comes out that the apparent donor density measured at high bending is different from the two donor densities used in fitting the $\mathrm{M}-\mathrm{S}$ plots.

Finally we want to stress that the introduction of several discrete donor levels distributed in energy would enhance the fitting of the experimental MottSchottky curves especially at low band bending (see inset of Fig. 9) by suggesting a resulting electronic structure of the crystalline semiconductor quite similar to that of an amorphous semiconductor. According to this and by taking into account the amorphous nature of the aged $\alpha-\mathrm{Nb}_{2} \mathrm{O}_{5}$ the more complex model of amorphous semiconductor has been used to exploit

Table 2. Parameters for the fitting reported in Figs. 6-9. The value $\Delta E_{\mathrm{F}}$ is not a parameter, but is obtained from Eq. (7). $U_{\mathrm{fb}}$ and $E_{\mathrm{C}}$ are given in the electrochemical scale with respect to the reference electrode SSC

\begin{tabular}{c|c|c|c|c|c|c|c}
\hline Figure & $U_{\mathrm{fb}}, \mathrm{V}$ & $N_{\mathrm{T}, 1}, \mathrm{~cm}^{-3}$ & $E_{\mathrm{C}}-E_{\mathrm{T}, 1} / k_{\mathrm{B}} T$ & $N_{\mathrm{T}, 2}, \mathrm{~cm}^{-3}$ & $E_{\mathrm{C}}-E_{\mathrm{T}, 2} / k_{\mathrm{B}} T$ & $\Delta E_{\mathrm{F}}, \mathrm{meV}$ & $E_{\mathrm{C}}, \mathrm{V}$ \\
\hline 6 & -0.3 & $8.2 \times 10^{18}$ & 0.5 & $4.6 \times 10^{19}$ & 24 & 93.3 & -0.39 \\
7 & -0.5 & $8.5 \times 10^{18}$ & 14 & $1.0 \times 10^{20}$ & 29 & 226 & -0.73 \\
8 & -0.48 & $7.5 \times 10^{18}$ & 16 & $1.1 \times 10^{20}$ & 28.5 & 253 & -0.73 \\
9 & -0.46 & $7.8 \times 10^{18}$ & 18 & $1.1 \times 10^{20}$ & 28.5 & 278 & -0.74 \\
\hline
\end{tabular}




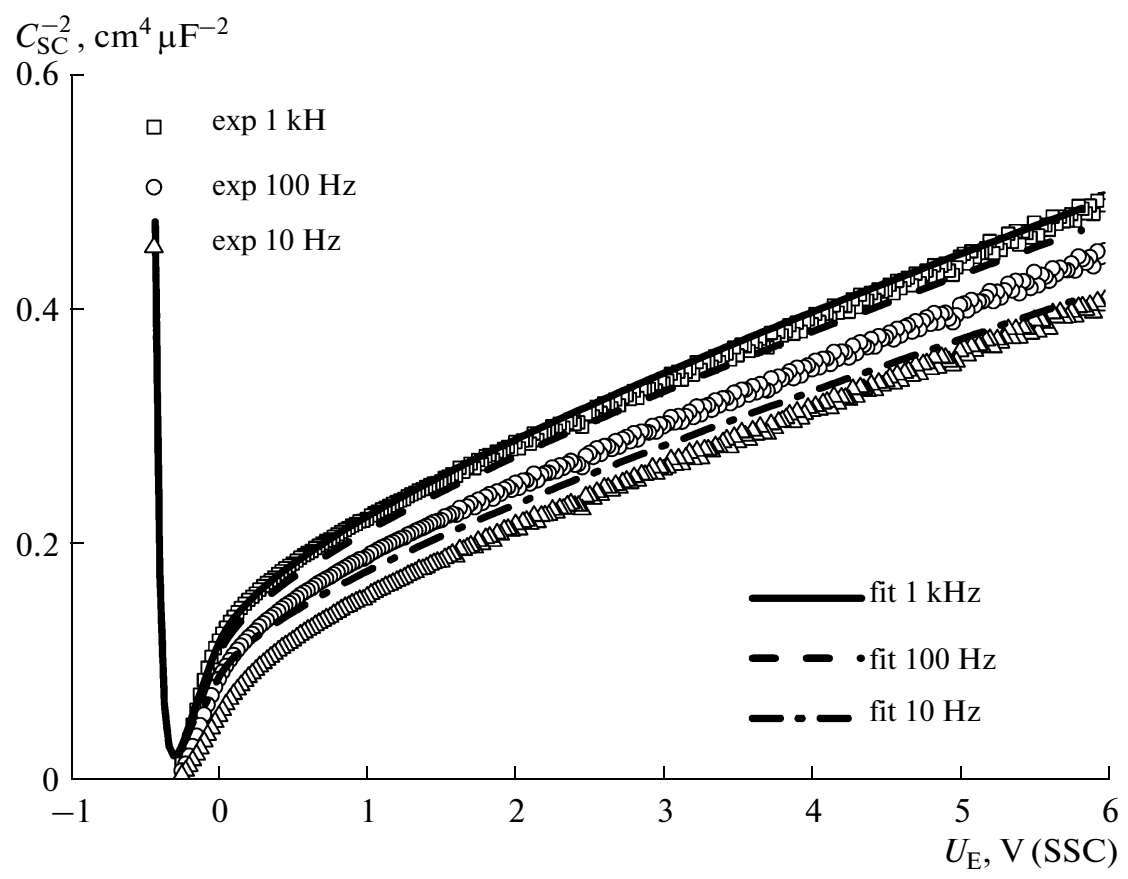

Fig. 8. Mott-Schottky plot and fitting curves at different frequencies in $0.5 \mathrm{M} \mathrm{H}_{2} \mathrm{SO}_{4}$, relating to aged $50 \mathrm{~V}$ anodic films on $\mathrm{Nb}$. The parameters of the fitting curves are: $U_{\mathrm{fb}}=-0.48 \mathrm{~V}$ vs. SSC; $N_{\mathrm{T}, 1}=7.5 \times 10^{18} \mathrm{~cm}^{-3}, E_{\mathrm{C}}-E_{\mathrm{T}, 1}=16 k_{\mathrm{B}} T ; N_{\mathrm{T}, 2}=1.1 \times 10^{20} \mathrm{~cm}^{-3}$, $E_{\mathrm{C}}-E_{\mathrm{T}, 2}=28.5 k_{\mathrm{B}} T .\left(\Delta E_{\mathrm{F}} \approx 253 \mathrm{meV}\right)$.

the ac answer of the junction in agreement with the theory of amorphous Schottky barriers.

\subsection{Amorphous Semiconductor (a-SC) Schottky Barrier Theory}

The Losee's mathematical treatment already discussed to get Eqs. (1) - (5) has been used for getting out the expression for the admittance of a-SC Schottky barrier [20] and for the a-SC/electrolyte junction [19] once the due differences in the electronic structure of amorphous materials are taken into account. With respect to the case of c-SC material the main difference in calculating the ac frequency answer of the aSC Schottky barrier comes out from the fact that owing to the existence of a finite density of states (DOS) within the mobility gap of a-SC the most part of electronic charge is now located below the Fermi level in localised states quite distant in energy from the conduction band mobility edge separating the extended states region from localised ones [3, 16, 20, $22,23,41]$. According to this the following expression for $\rho_{\mathrm{SL}}$ and $\rho_{\mathrm{DL}}$ are used in equations $(6 \mathrm{c})-(6 \mathrm{f})$ :

$$
\begin{gathered}
\rho_{\mathrm{SL}}(\psi)=0, \\
\rho_{\mathrm{DL}}(\psi)=|\mathrm{e}| \int_{E_{\mathrm{F}}-|\mathrm{e}| \psi}^{E_{\mathrm{F}}} N(E) d E .
\end{gathered}
$$

where the first condition means that the concentration of electron carriers in the extended states above the mobility edge of a-SC is now negligible with respect to the electronic charge deep lying in localized states within the mobility gap of a-SC and below the equilibrium Fermi level. By using expressions (14a)-(14b), under hypothesis of an almost constant (or slightly changing with energy) electronic DOS, an analytical solution can be obtained as firstly shown in Refs. [20, 24].

In previous works we presented and discussed the use of a-SC Schottky barrier theory in the case of different semiconducting passive films/electrolyte junctions [16-19, 42] both in the low and high band bending regime [43], so that details of the theory will be omitted here. In these works [20,23] it was shown that the admittance of the a-SC Schottky junction is composed by an imaginary, $C_{\mathrm{SC}}$, and a real, $G_{\mathrm{SC}}$, part, both depending on frequency and potential. It was suggested [23] that the capacitance, $C_{\mathrm{SC}}$, is weakly influenced by a non uniform DOS, provided that changes of DOS are small for energy changes in the order of $k_{\mathrm{B}} T$. In this case an average value of DOS is obtained from $C_{\mathrm{SC}}$. According to this we proposed the following expressions in presence of a non-constant DOS:

$$
\begin{aligned}
& \frac{1}{C_{\mathrm{SC}}\left(\omega, \psi_{\mathrm{S}}\right)} \\
& =\frac{1}{\sqrt{\varepsilon|\mathrm{e}|^{2} N_{\mathrm{av}}}}\left\{\ln \left(\frac{\psi_{\mathrm{g}}}{\psi_{\mathrm{C}}}\right)+\sqrt{1+\frac{2}{\psi_{\mathrm{g}}}\left(\psi_{\mathrm{S}}-\psi_{\mathrm{g}}\right)}\right\} \text {, }
\end{aligned}
$$




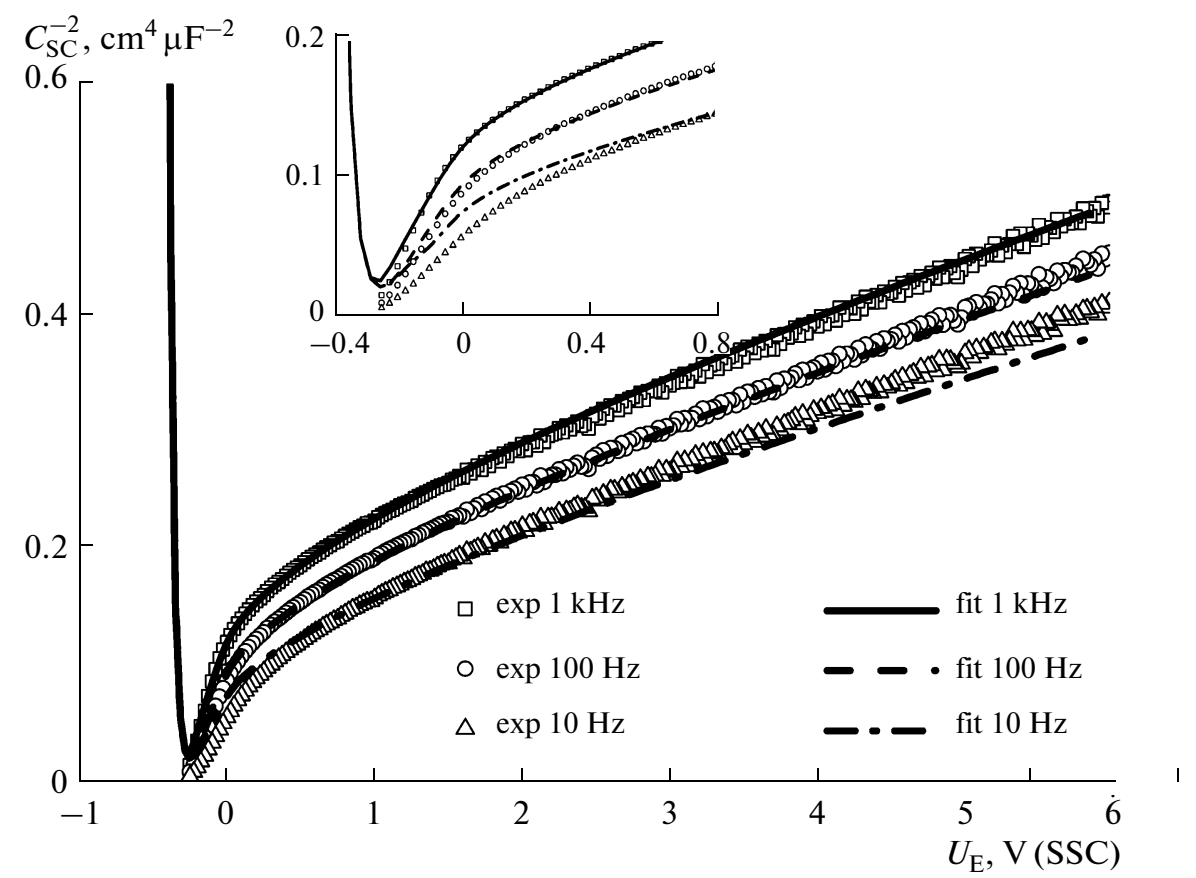

Fig. 9. Mott-Schottky plot and fitting curves at different frequencies in $0.5 \mathrm{M} \mathrm{H}_{2} \mathrm{SO}_{4}$, relating to aged $50 \mathrm{~V}$ anodic films on $\mathrm{Nb}$. The parameters of the fitting curves are: $U_{\mathrm{fb}}=-0.46 \mathrm{Vvs}$. SSC; $N_{\mathrm{T}, 1}=7.8 \times 10^{18} \mathrm{~cm}^{-3}, E_{\mathrm{C}}-E_{\mathrm{T}, 1}=18 k_{\mathrm{B}} T, N_{\mathrm{T}, 2}=1.1 \times 10^{20} \mathrm{~cm}^{-3}$, $E_{\mathrm{C}}-E_{\mathrm{T}, 2}=28.5 k_{\mathrm{B}} T .\left(\Delta E_{\mathrm{F}} \approx 278 \mathrm{meV}\right)$.

$$
\begin{gathered}
G_{\mathrm{SC}}\left(\omega, \psi_{\mathrm{S}}\right)=\pi^{2} \mathrm{f} \frac{k_{\mathrm{B}} T}{|\mathrm{e}| \psi_{\mathrm{C}}} \sqrt{\varepsilon|\mathrm{e}|^{2} N_{\mathrm{av}}} \frac{N}{N_{\mathrm{av}}} \\
\times\left\{\ln \left(\frac{\psi_{\mathrm{g}}}{\psi_{\mathrm{C}}}\right)+\sqrt{1+\frac{2}{\psi_{\mathrm{g}}}\left(\psi_{\mathrm{S}}-\psi_{\mathrm{g}}\right)}\right\}^{-2},
\end{gathered}
$$

provided that: $\psi_{\mathrm{S}} \geq \psi_{\mathrm{C}} \geq 3 k_{\mathrm{B}} T /|\mathrm{e}| . N_{\mathrm{av}}$ represents an averaged DOS between 0 and $x_{\mathrm{C}}$ for $C\left(\psi_{\mathrm{S}}, \omega\right)$, and $N$ is the DOS at $x_{\mathrm{C}}$ and energy $E=E_{\mathrm{F}}-|\mathrm{e}| \psi_{\mathrm{C}}$ (the conductance has a more spectroscopic character than the capacitance). The symbols used in previous equations are defined in Fig. 10 showing the energetics of a-SC/electrolyte junction. According to Fig. 10:

(a) $\psi_{\mathrm{S}}=U_{\mathrm{E}}-U_{\mathrm{FB}}$ represent the band bending of the a-SC with respect to the flat band condition $\left(\psi_{\mathrm{S}}=0\right)$;

(b) $\psi_{\mathrm{g}}$ represents the band bending at $x_{\mathrm{g}}$ and it corresponds to the electrode potential drop $U_{\mathrm{g}}$ at which the quasi Fermi level, $E_{\mathrm{F}}$, inside the a-SC ceases to be constant and it marks the beginning of the high band bending regime. In the hypothesis of constant capture/emission rate of electrons and hole, from localized state to their respective band, $\psi_{\mathrm{g}}$ is given by the expression:

$$
|\mathrm{e}| \psi_{\mathrm{G}}=\frac{E_{\mathrm{g}}}{2}-\Delta E_{\mathrm{F}}
$$

(c) $\psi_{\mathrm{C}}$ is the band bending at the characteristic point $x_{\mathrm{C}}$ within the space charge region of a-SC where the quasi-Fermi level of the junction intersects the cut-off energy level, $E_{\omega}$. This last level is defined according to the relationship:

$$
E_{\mathrm{C}}-E_{\omega}=-k_{\mathrm{B}} T \ln \left(\omega \tau_{0}\right),
$$

where, at constant temperature, $\tau_{0}$ is a time constant characteristic of each material usually ranging between $10^{-4}$ and $10^{-10} \mathrm{~s}$. According to Fig. 10 the corresponding band bending $\psi_{\mathrm{C}}$ is defined by:

$$
|\mathrm{e}| \psi_{\mathrm{C}}=|\mathrm{e}| \psi\left(x_{\mathrm{C}}\right)=-k_{\mathrm{B}} T \ln \left(\omega \tau_{0}\right)-\Delta E_{\mathrm{F}},
$$

where $\Delta E_{\mathrm{F}}=\left(E_{\mathrm{C}}-E_{\mathrm{F}}\right)_{\text {bulk }} \cdot x_{\mathrm{C}}$ is now a distance in the barrier which changes with changing angular frequency, $\omega$, and band bending $\psi_{\mathrm{S}}$. In particular $x_{\mathrm{C}}$ increases with increasing frequency, at constant polarization, or with increasing polarization at constant frequency. At high band bending the total capacitance of the junction is the sum of three series contributions originating from:

(1) the region $0<x<x_{\mathrm{g}}$ which behaves as a dielectric, frequency independent, but which widens with increasing potential;

(2) the region $x_{\mathrm{g}}<x<x_{\mathrm{C}}$ (null response region) which behaves as a dielectric and whose response is frequency and potential depending;

(3) the region $x>x_{C}$ (total response region) of the a-SC which is frequency independent as well potential independent as long as spatially homogeneous DOS distribution is present inside the a-SC.

The contribution to the conductance of a-SC Schottky barrier comes mainly from the region around $x=x_{\mathrm{C}}$, which divides the total response from null 

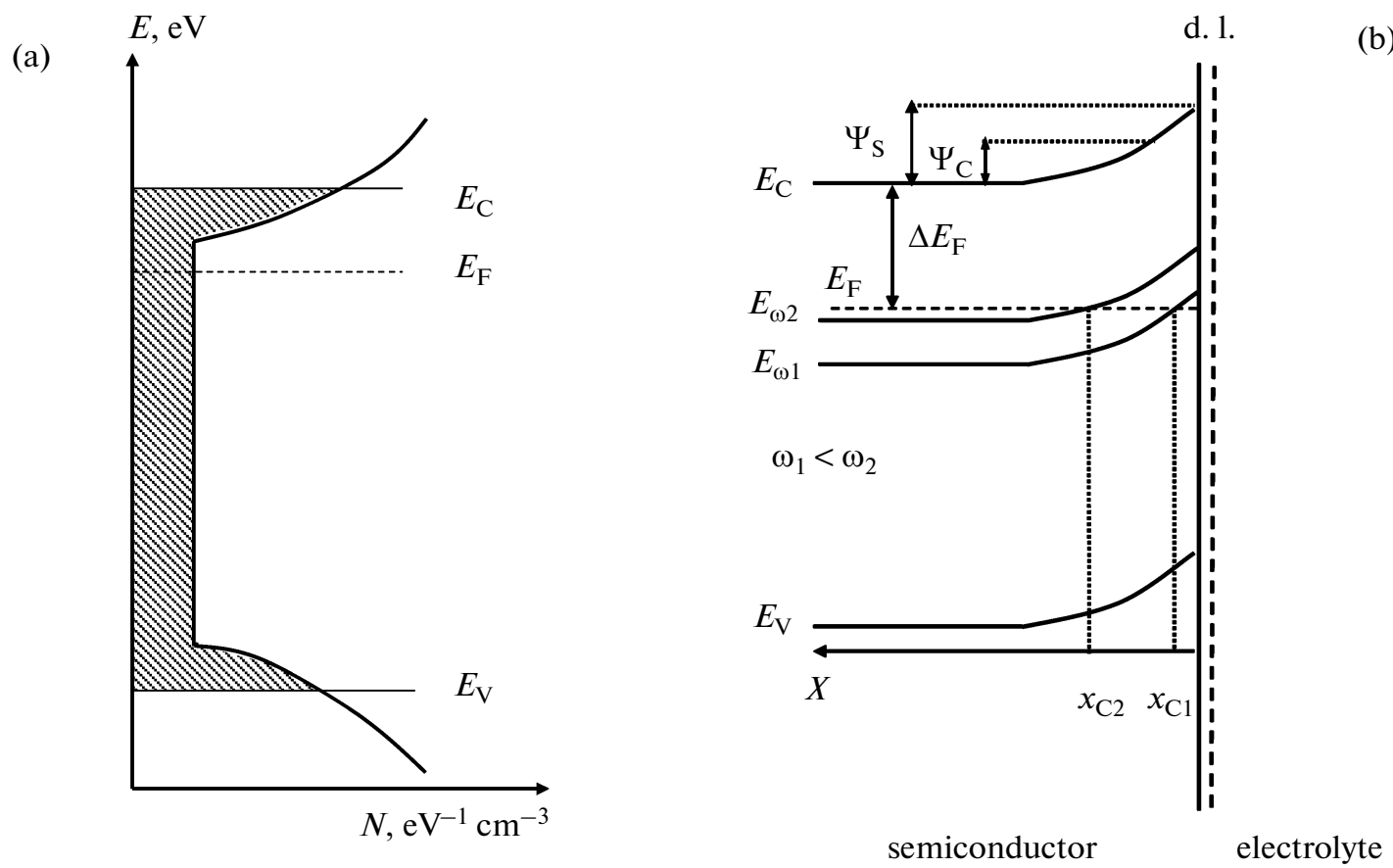

Fig. 10. Electronic structure (a) and band bending distribution (b) across an $n$-type a-SC/Electrolyte interface.

response regions and it shows a spectroscopic character with respect to the local DOS distribution, as shown in Eq. (15b).

The $C_{\mathrm{SC}}$ and $G_{\mathrm{SC}}$ equations above reported (Eq. (15a)-(15b)) contain as limiting case the low band bending regime $\left(\psi_{\mathrm{S}}<\psi_{\mathrm{g}}\right)$ as well as me hypothesis of constant DOS $\left(N_{\mathrm{av}}=N\right)$ for which case the analytical expressions both in low band bending and high band bending regime have been reported in literature $[16,20,24,43]$. At variance with the case of crystalline $\mathrm{SC}$ the location of conduction (valence) band mobility edge for $n$-type ( $p$-type) a-SC it is now carried out according to Eq. (18) once the flat band location has been determined. The flat band potential of the junction is now a fitting parameter for both components of the admittance assumed to remain constant, within $k_{\mathrm{B}} T /|\mathrm{e}|$, with changing frequencies [16].

In Fig. 11 we report the fitted capacitance vs. potential plots according to the theory of a-SC Schottky barrier for the same frequencies previously used in $\mathrm{M}-\mathrm{S}$ analysis. The fitting parameters at the different frequencies are those reported in the caption but a more detailed study of the fitting process can be found in a previous work $[19,26]$. By a trial and error procedure and by imposing the constraints on the flat band potential $\left(U_{\mathrm{fb}}\right.$ constant at any frequency for which $\left.\psi_{\mathrm{C}} \geq 3 k_{\mathrm{B}} T /|\mathrm{e}|\right)$ and on $\psi_{\mathrm{C}}$ :

$$
\frac{d \psi_{\mathrm{C}}}{d \log \mathrm{f}}=\frac{k_{\mathrm{B}} T}{|\mathrm{e}|} \times 2.303
$$

(see Eq. (18)) we get the best fitting by introducing also a spatially variable DOS [16]. According to this proce- dure we get for both components of the admittance a constant flat band potentially $\left(U_{\mathrm{fb}}=-0.377 \pm 0.015 \mathrm{~V}\right.$ vs. SSC) independent from the frequency. Finally it may be of some interest to mention that the $U_{\mathrm{fb}}$ value derived from the best fitting procedure of the admittance curves is very near to the potential intercept value obtained by extrapolating to zero the $C_{\mathrm{SC}}^{-2}$ vs. $U_{\mathrm{E}}$ plot depicted in Fig. 11. We like to mention that both the frequency dependence as well the non linear potential dependence of $C_{\mathrm{SC}}^{-2}$ plots at various frequency and in the low band bending region are physically explained in the frame of the theory of a-SC Schottky barrier.

However in order to better elucidate the relationship between the $\mathrm{M}-\mathrm{S}$ approach and the a-SC theory it may be of interest to derive the slope of the $\mathrm{M}-\mathrm{S}$ plots at high band bending regime, in the frame of a-SC Schottky barrier theory, and to compare such an expression with the usual expression derived from $\mathrm{M}-\mathrm{S}$ analysis. By using the expression for the capacitance of a-SC/electrolyte junction reported above (see Eq. (15a)) it is possible to derive for the slope of the $\mathrm{M}-\mathrm{S}$-like equation the following expression:

$$
\frac{d}{d \psi_{\mathrm{S}}}\left(\frac{1}{C_{\mathrm{SC}}^{2}}\right)=\left(\frac{2}{\varepsilon|\mathrm{e}|^{2} N_{\mathrm{av}} \psi_{\mathrm{G}}}\right)\left[1+\frac{\ln \left(\frac{\psi_{\mathrm{G}}}{\psi_{\mathrm{C}}}\right.}{\sqrt{2 \frac{\psi_{\mathrm{S}}}{\psi_{\mathrm{G}}}}}\right] .
$$




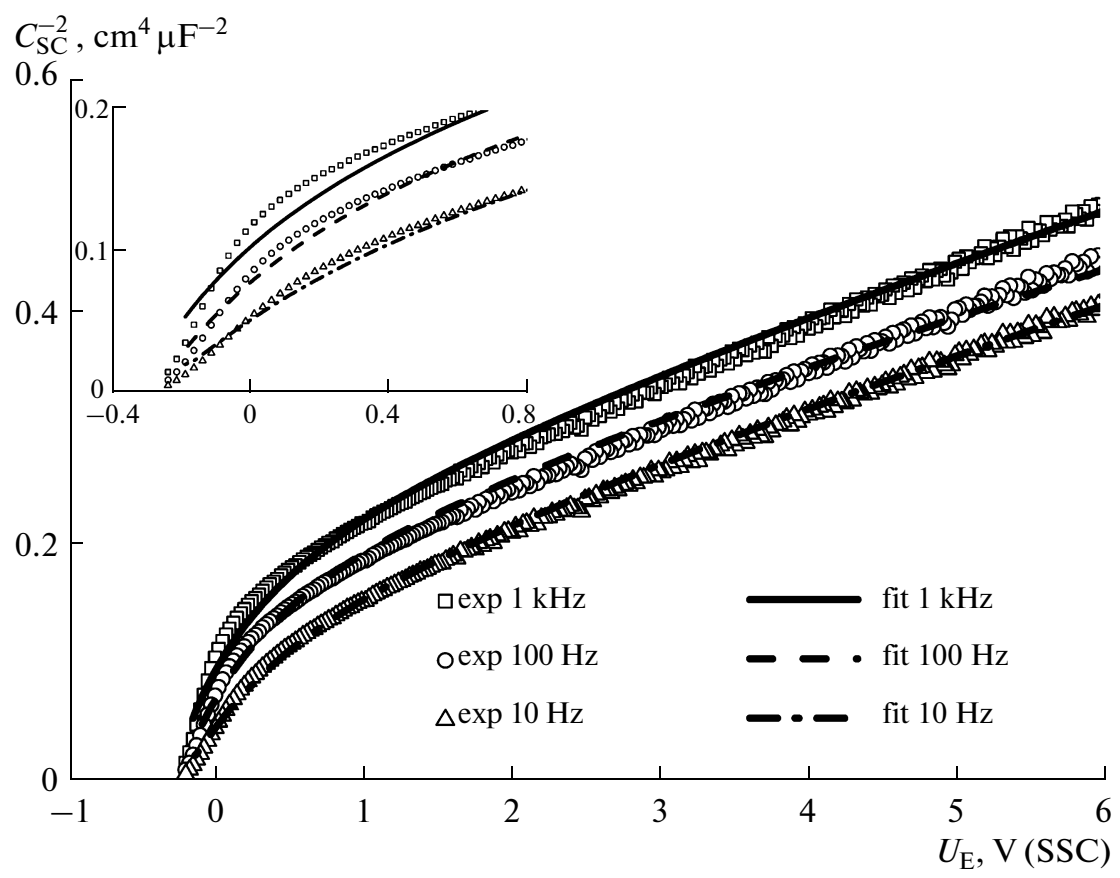

Fig. 11. Mott-Schottky plot and fitting curves at different frequencies in $0.5 \mathrm{M} \mathrm{H}_{2} \mathrm{SO}_{4}$, relating to aged $50 \mathrm{~V}$ anodic films on $\mathrm{Nb}$. The a-SC theory was used (see Ref. [26]). $U_{\mathrm{fb}}=-0.377 \pm 0.015 \mathrm{Vvs}$. SSC ( $\Delta E_{\mathrm{F}} \approx 373 \mathrm{meV} ; E_{\mathrm{C}}=-0.75 \mathrm{~V}$ vs. SSC).

It is easy to show, by direct substitution of the different fitting parameters, $\psi_{\mathrm{G}}$ and $\psi_{\mathrm{C}}$, that the term in the square brackets:

(1) at fixed band bending, $\psi_{\mathrm{S}}$, it is very weakly depending from the ac frequency owing to the logarithm dependence of $\psi_{\mathrm{C}}$ from the ac frequency;

(2) at fixed frequency (constant $\psi_{\mathrm{C}}$ ) it is also weakly depending from the band bending in a rather large range of electrode potential as those reported in Fig. 11.

This weakly dependence of the square bracket term, in presence of a spatially almost constant average DOS, is at the origin of the almost constant slope in the $\mathrm{M}-\mathrm{S}$ analysis of the differential capacitance curves for $\alpha-\mathrm{Nb}_{2} \mathrm{O}_{5}$ aged film. When this occurs it is possible to derive, from the previous equation, an average value of DOS near the Fermi level of the a-SC (see Table 3).

Moreover at fixed frequency, i.e. constant $\psi_{\mathrm{C}}$ value, and at high band bending values the square bracket term tends to unity and a Mott-Schottky-like behaviour appears in the differential capacitance vs. potential plots. When such high band bending region is accessible the extrapolation to zero of $C_{\mathrm{SC}}^{-2}$ vs. $U_{\mathrm{E}}$ plot does not give the true flat band potential (see Fig. 4) neither the "true donor density" but, as discussed above, it is possible to get a rough information on the DOS of a-SC.

More detailed information both on the spatial and energy dependence of electronic DOS of a-SC can be derived by fitting the admittance vs. potential plots at different frequencies as discussed in several older papers for anodic niobia and anodic tungsten oxide electrodes $[4,16-18]$ and more recently for thermally aged niobia grown on sputtered metal [26]. According to the theory $[16,26]$, owing to the more spectroscopic character of the conductance, originating in a very narrow region of the barrier around $x_{\mathrm{C}}$, it is possible from the curves plotted in Fig. 12 to derive the spatial distribution of the DOS at the energy level $\left(E_{\mathrm{F}}-|\mathrm{e}| \psi_{\mathrm{C}}\right)$ (fixed frequency) as a function of the distance from the metal/oxide interface. On the other hand from the same curves, at any point $x_{\mathrm{C}}$ within the space charge region, it is possible to get the DOS distribution as a function of the energy (from different curves). Interestingly it comes out that at each frequency the total DOS variation from the low band-bending to the high band-bending region amounts to less than a factor two. This figure should be compared with the much larger increase reported in Table 1 and Table 2 for the donor density derived in the two regions according to the $\mathrm{M}-\mathrm{S}$ theory of crystalline semiconductor.

Table 3. Value of $\psi_{\mathrm{C}}$ and $N_{\mathrm{av}}$ (obtained from Eq. (20)) at different frequencies

\begin{tabular}{r|c|c}
\hline$f, \mathrm{~Hz}$ & $\psi_{\mathrm{C}}, \mathrm{meV}$ & $N_{\mathrm{av}}, \mathrm{cm}^{-3} \mathrm{eV}^{-1}$ \\
\hline 1000 & 112 & $7.8 \times 10^{19}$ \\
100 & 171 & $7.5 \times 10^{19}$ \\
10 & 230 & $7.2 \times 10^{19}$ \\
\hline
\end{tabular}

No. $11 \quad 2010$ 


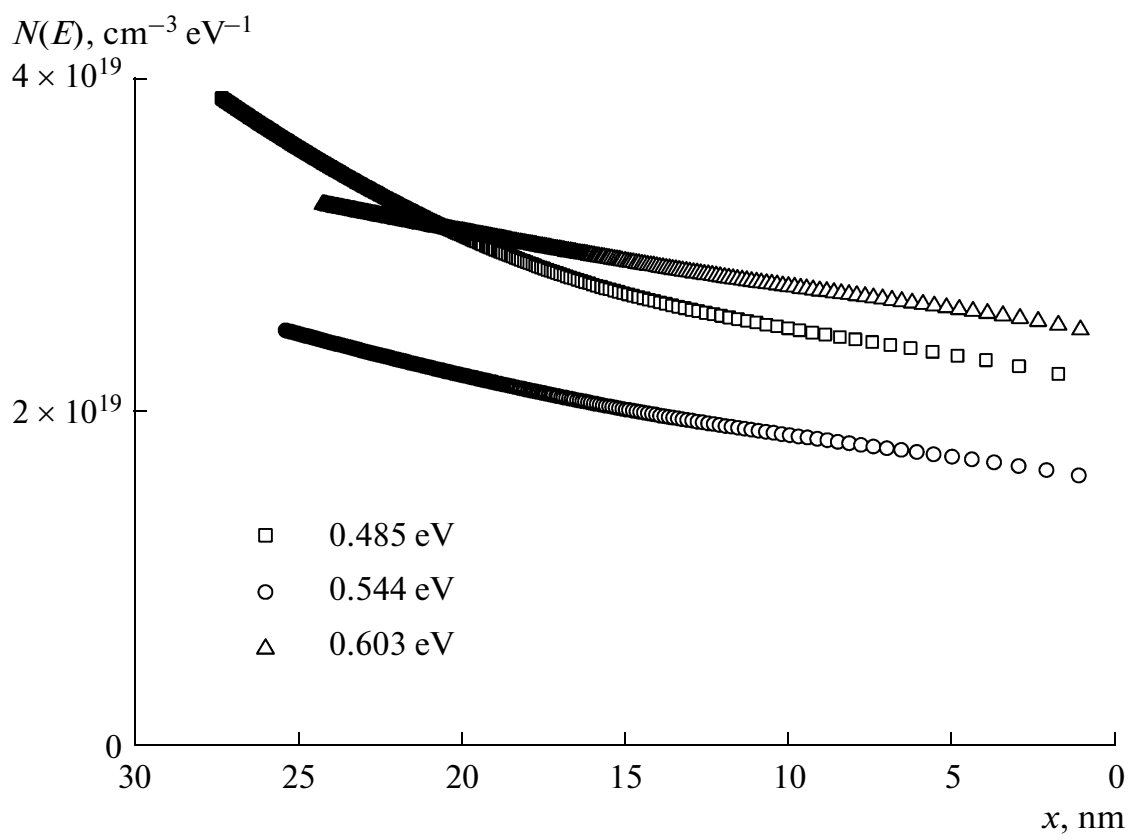

Fig. 12. Spatial distribution of the DOS at different energy level, obtained from the fitting of $G_{\mathrm{SC}}$ and $C_{\mathrm{SC}}$ (see Fig. 3). The distance in energy from the conduction band is given in the legend.

These finding can help to rationalize some of the experimental results reported in literature of passive film [44] and left unexplained, moreover it show unequivocally that the usual description of semiconducting behaviour of passive film by means of the theory of crystalline semiconductor is misleading because it does not provide a correct physical insights on the solid state properties of passive film and it can provide seriously erroneous information on the location of the energy levels of the passive film/electrolyte interface.

\subsection{Location of Characteristic Energy Levels (Energetics) of the Junction}

In order to highlight this last aspect we like to compare the results pertaining to the location of the characteristic energy level of the junction: the conduction band mobility edge for $\alpha-\mathrm{Nb}_{2} \mathrm{O}_{5} / \mathrm{El}$. and the conduction band edge, $E_{\mathrm{C}}$, if we assume the theory of crystalline semiconductor. In this last case the location of conduction band edge it is carried out by means of equation:

$$
\Delta E_{\mathrm{F}}=E_{\mathrm{C}}-E_{\mathrm{F}}=k_{\mathrm{B}} T \ln \left(\frac{N_{\mathrm{C}, \text { eff }}}{N_{\mathrm{D}}}\right),
$$

where $\Delta E_{\mathrm{F}}$ represents the distance in energy of the conduction band from the Fermi level of the semiconductor, $N_{\mathrm{C}, \text { eff }}$ is the effective density of states at the conduction band edge and $N_{\mathrm{D}}$ is the density of donor derived from the $\mathrm{M}-\mathrm{S}$ plots.

In the case of a-SC the energy distance $\Delta E_{\mathrm{F}}$ is obtained by means of Eq. (18) once a values of $\psi_{C}$ at a single frequency is known or, more correctly, by extrapolating to $\psi_{\mathrm{C}}=0$ the measured $\psi_{\mathrm{C}}$ values at different frequencies and by using the corresponding angular frequency, $\omega_{0}$, and the Eq. (22):

$$
\Delta E_{\mathrm{F}}=-k_{\mathrm{B}} T \ln \left(\omega_{0} \tau_{0}\right) .
$$

In absence of further information, an average $\tau_{0}$ value around $10^{-12} \mathrm{~s}$ can be used in equation (22). This leaves an uncertainty of less than $0.12 \mathrm{eV}$ in the $E_{\mathrm{C}}\left(E_{\mathrm{V}}\right)$ location which is an acceptable value by taking into account the absence of any sharpness in the mobility edge of a-SC separating electronic extended states from localized ones [41].

In the hypothesis of crystalline semiconductor it comes out that the $E_{\mathrm{C}}$ level of niobia is located at around $0.093 \pm 0.01 \mathrm{eV}$ above the Fermi level of the junction if we assume an average donor density of $8.2 \times$ $10^{18} \mathrm{~cm}^{-3}$ derived from the low band bending region and an effective density of state at $E_{\mathrm{C}}\left(N_{\mathrm{C}, \text { eff }}\right)$ equal to $3 \times 10^{20} \mathrm{~cm}^{-3}$ derived by assuming an effective electron mass, $m^{*}$, equal to 5 for niobia. Such a value of effective electron mass has been chosen in order to keep the $\Delta E_{\mathrm{F}} \geq 3 k_{\mathrm{B}} T$ as requested by the simplified $\mathrm{M}-\mathrm{S}$ theory for the validity of Eq. (21). A still larger effective electron mass $\left(m^{*} \approx 22\right)$ is necessary to keep the constraint $\Delta E_{\mathrm{F}} \geq 3 k_{\mathrm{B}} T$, if we used the value of donor density $(\sim 5 \times$ $10^{19} \mathrm{~cm}^{-3}$ ) derived from $\mathrm{M}-\mathrm{S}$ plots in the high band bending regime. In presence of so highly doped semiconductor, as usually reported in the literature of passive film, the simple $\mathrm{M}-\mathrm{S}$ analysis have to be abandoned in favour of more complex mathematical treatment as suggested in Ref. [45]. We like to mention that for donor density around $10^{21} \mathrm{~cm}^{-3}$ (a value frequently 
encountered in the literature of passive film) the concept of space charge region appears meaningless owing to the fact that its dimension becomes comparable to the semiconductor lattice dimensions. We have to say that such very high values of donor density probably reflect more serious limitations in the use of simple $\mathrm{M}-\mathrm{S}$ theory related to the presence of further complications originated by the extreme thinness of passive films, by the possible contribution of electronic surface states to the measured differential capacitance values and/or inadequate equivalent electrical circuit $[34,35]$. We like to stress that in our case the width of space charge region at the highest band bending amounts to less than $30 \%$ of the total niobia thickness.

In the case of amorphous material the use of Eq. (22) allows to locate the mobility edge of aged $\alpha-\mathrm{Nb}_{2} \mathrm{O}_{5}$ at around $0.37 \mathrm{eV}$ from the Fermi level $\left(\Delta E_{\mathrm{F}}=0.373 \mathrm{eV}\right)$ so fixing this characteristic level of the thermally aged amorphous niobium oxide about $-0.75 \mathrm{~V}$ vs. SSC (around $-0.55 \mathrm{~V}$ vs. NHE). This level is also appreciably $(\approx 0.35 \mathrm{~V})$ more cathodic than the conduction band level derived for $E_{\mathrm{C}}$ according to the Mott-Schottky theory, and almost coincide with the value obtained for the two deep donor level case (see Fig. 9 and Table 2). This finding can help to explain the kinetic of electron exchange at the interface between oxidized niobium metal and different redox couples in solution reported in literature [46, 47]. Moreover the favourable position of the niobia Fermi level more cathodic than the equilibrium potential of hydrogen redox couple is an interesting aspect for the possible use of such a material in photoelectrochemical cell for direct solar splitting of water.

\section{CONCLUSIONS}

Simple Mott-Schottky analysis of the differential capacitance data have been shown to provide misleading information on the characteristic energy levels of the semiconductor/electrolyte junction specially in the case of passive film having strongly disordered crystallographic structure originating a possible distribution of deeply localized donor levels. The appearance of frequency depending $\mathrm{M}-\mathrm{S}$ plots, once excluded the presence of a surface state contribution to the measured capacitance, is a strong indication in favour of the existence of deep lying donor levels the whose concentration and energy location affect both the estimated flat band potential and apparent donor density values. The choice of a single frequency to characterise the passive film/electrolyte junction should be avoided owing to the loss of information about the real electronic structure of passive film. It should be mentioned that the above analysis has been carried out in the hypothesis that the space charge region in amorphous and crystalline semiconductor is much less than the thickness of the semiconductor electrode, this is a relevant constraint in the analysis of the experimental data for the case of passive film usu- ally few nanometers thick. Further studies on the influence of a limited thickness on the capacitance behaviour of passive film/electrolyte junction are necessary to reach a deeper understanding of the electronic structure of thin passive film. Finally we like to mention that the simplifying assumption of an ideally polarizable interface, allowing the use of a simplified electrical equivalent circuit for the electrode/electrolyte interface, should be carefully checked and, where possible, the experimental conditions should have to be modified to accomplish such a condition.

\section{REFERENCES}

1. Gerischer, H., Electrochim. Acta, 1990, vol. 35, p. 1677.

2. Gerischer, H., Corrosion Sci., 1989, vol. 29, 257.

3. Di Quarto, F., La Mantia, F., and Santamaria, M., Modern Aspects of Electrochemistry, vol. 46, New York: Springer, 2009, p. 217.

4. Harrington, S.P. and Devine, T.M., J. Electrochem. Soc., 2008, vol. 155, p. C381.

5. Di Quarto, F. and Santamaria, M., Corrosion Eng. Sci. Tech., 2004, vol. 39, p. 71.

6. Gerischer, H., J. Electroanal. Chem., 1977, vol. 82, p. 133.

7. Gerischer, H., J. Vac. Sci. Tech., 1978, vol. 15, p. 1422.

8. Bard, A.J. and Wrighton, M.S., J. Electrochem. Soc., 1977, vol. 124, p. 1706.

9. Brattain, W.H. and Garrett, C.G.B., Phys. Rev., 1954, vol. 94, p. 750.

10. Boddy, P.J. and Brattain, W.H., J. Electrochem. Soc., 1963, vol. 110, p. 70.

11. Dewald, J.F., Bell Syst. Tech. J., 1960, vol. 39, p. 615.

12. Dewald, J.F., J. Phys. Chem. Solid, 1960, vol. 14, p. 155.

13. Green, M., Modern Aspects of Electrochemistry, vol. 2, London: Butterworths, 1959, p. 343.

14. Myamlin, V.A. and Pleskov, Y.V., Electrochemistry of Semiconductors, New York: Plenum Press, 1967.

15. Hamnett, A., Comprehensive Chemical Kinetics, vol. 27, Oxford: Elsevier Science, 1987, p. 61.

16. Di Quarto, F., La Mantia, F., and Santamaria, M., Electrochim. Acta, 2005, vol. 50, p. 5090.

17. Di Quarto, F., La Mantia, F., and Santamaria, M., Passivation of Metals and Semiconductors, and Properties of Thin Oxide Layers, Paris: Elsevier, 2006, p. 343.

18. Di Quarto, F., La Mantia, F., and Santamaria, M., Corrosion Sci., 2007, vol. 49, p. 186.

19. La Mantia, F., Santamaria, M., Habazaki, H., and Di Quarto, F., ECST, 2009, vol. 19, p. 411.

20. Cohen, J.D. and Lang, D.V., Phys. Rev. B, 1982, vol. 25, p. 5321.

21. Lang, D.V., Cohen, J.D., and Harbison, J.P., Phys. Rev. $B, 1982$, vol. 25 , p. 5285 .

22. Abram, R.A., and Doherty, P.J., Phil. Mag. B, 1982, vol. 45, p. 167.

23. Archibald, I.W. and Abram, R.A., Phil. Mag. B, 1983, vol. 48, p. 111.

24. Archibald, I.W. and Abram, R.A., Phil. Mag. B, 1986, vol. 54, p. 421. 
25. Habazaki, H., Ogasawara, T., Konno, H., Shimizu, K., Asami, K., Saito, K., Nagata, S., Skeldon, P., and Thompson, G.E., Electrochim. Acta, 2005, vol. 50, p. 5334.

26. Habazaki, H., Yamasaki, M., Ogasawara, T., Fushimi, K., Konno, H., Shimizu, K., Izumi, T., Matsuoka, R., Skeldon, P., and Thompson, G.E., Thin Solid Films, 2008, vol. 516, p. 991.

27. Habazaki, H., Matsuo, T., Konno, H., Shimizu, K., Matsumoto, K., Takayama, K., Oda, Y., Skeldon, P., and Thompson, G.E., Surface and Interface Analysis, 2003, vol. 35, p. 618. 28. La Mantia, F., Santamaria, M., Di Quarto, F., and Habazaki, H., J. Electrochem. Soc., 2010, vol. 157, p. C258.

29. Schneider, M., Schroth, S., Schilm, J., and Michaelis, A., Electrochim. Acta, 2009, vol. 54, p. 2663.

30. Kong, D.S., Lu, W.H., Feng, Y.Y., Yu, Z.Y., Wu, J.X., Fan, W.J., and Liu, H.Y., J. Electrochem. Soc., 2009, vol. 156, p. C39.

31. Harrington, S.P. and Devine, T.M., J. Electrochem. Soc., 2009, vol. 156, p. C154.

32. Lu, Z.J. and Macdonald, D.D., Electrochim. Acta, 2008, vol. 53, p. 7696.

33. Cardon, F. and Gomes, W.P., J. Phys. Appl. Phys., 1978, vol. 11, p. L63.

34. Morrison, S.R., Electrochemistry at Semiconductor and Oxidized Metal Electrodes, New York: Plenum Press, p. 1980.
35. Hamnett, A., Comprehensive Chemical Kinetics, vol. 27, Oxford: Elsevier Science, 1987, p. 100.

36. Bockris, J.O. and Khan, S.U.M., Surface Electrochemistry, New York: Plenum Press, p. 1993.

37. Di Quarto, F., Sunseri, C., Piazza, S., and Santamaria, M., in Handbook of Thin Films, Nalwa, H.S., Ed., San Diego: Academic Press, 2002, vol. 2, p. 373.

38. Losee, D.L., J. Appl Phys., 1975, vol. 46, p. 2204.

39. Dean, M.H. and Stimming, U., Corrosion Sci., 1989, vol. 29, p. 199.

40. Dean, M.H. and Stimming, U., J. Electroanal. Chem., 1987, vol. 228, p. 135.

41. Mott, F.N. and Davis, E.A., Electronic Processes in Non-crystalline Materials, Oxford: Clarendon Press, 1979, p. 373.

42. Di Quarto, F., Sunseri, C., and Piazza, S., Ber. Bunsen Phys. Chem., 1986, vol. 90, p. 549.

43. da Fonseca, C., Ferreira, M.G., and da Cunha Belo, M., Electrochim. Acta, vol. 39, 1994, p. 2197.

44. McAleer, J.F. and Peter, L.M., Faraday Discuss., 1980, vol. 70, p. 67.

45. Gerischer, H., J. Phys. Chem., 1985, vol. 89, p. 4249.

46. Heusler, K.E. and Schulze, M., Electrochim. Acta, 1975, vol. 20, p. 237.

47. Munoz, A.G. and Staikov, G., J. Solid State Electrochem., 2006, vol. 10, p. 329. 